\title{
NUEVOS DATOS SOBRE ARQUITECTURA DE PRESTIGIO IBÉRICA. LA REGIA DE "LAS TRES HERMANAS" (ASPE, ALICANTE)
}

\author{
JOSÉ RAMÓN GARCÍA GANDÍA \\ JESÚS MORATALLA JÁVEGA \\ Universidad de Alicante
}

\begin{abstract}
Presentamos en este artículo un edificio de carácter singular, emplazado en el yacimiento ibérico denominado Las Tres Hermanas de la localidad de Aspe, provincia de Alicante. Este estudio se incluye dentro del proyecto de investigación que se está llevando a cabo en los términos municipales de Aspe, Hondón de las Nieves y Hondón de los Frailes, así como en el ámbito general de la Contestania.

Este edificio, dado su carácter excepcional, constituye una muestra de la capacidad constructiva ibérica dentro de la koinè cultural mediterránea. Es producto de una sociedad que manifiesta su poder en un marco cronológico del siglo IV a.n.e. donde interactúan las influencias mediterráneas con otras de origen local.
\end{abstract}

In this study we present an important structure located in the lberic site of Las Tres Hermanas (Aspe, Alicante). The study is included on research project we carry out in Aspe, Hondón de las Nieves and Hondón de los Frailes, as well as in all the Contestania.

Due to its exceptional nature, the structure represents the lberic way of building in the Mediterranean cultural koiné. Showed its power in the IV century BC, when Mediterranean influences mixed with local ones.

\section{HISTORIA DE LA INVESTIGACIÓN}

La prospección del término municipal de Aspe, con el objeto de realizar una carta arqueológica elaborada por uno de nosotros, nos ha permitido localizar una estructura arquitectónica que consideramos de notable interés, amén de otros restos constructivos, cuya presentación es la finalidad de este trabajo.

Las primeras noticias acerca del yacimiento se remontan a la década de los 80 , cuando se deposita en el Museo Arqueológico Provincial de Alicante una bolsa con materiales atribuibles a la Edad del Bronce, en número reducido, y otros más numerosos de origen ibérico, todo ello fruto de recogidas superficiales. No obstante, nosotros conocemos la existencia del asentamiento a través de una comunicación personal con un aficionado de Aspe en 1995', quien nos informó sobre el abundante material cerámico en superficie que existía en el paraje denominado "Las Tres Hermanas".
Tras la autorización del permiso de prospección correspondiente por parte de la Conselleria de Cultura, Educaciò i Ciència, concedido a uno de nosotros en octubre de 1998, visitamos el yacimiento constatando la existencia de la planta de un edificio totalmente excavado, producto de una actuación clandestina, y junto a ella dos terreras, una antigua, colmatada, donde habían crecido las plantas, y otra con menos de un año de antigüedad, ya que no tenía vegetación encima. Esta circunstancia fue comunicada a la Unidad Técnica de Arqueología de la Dirección Territorial de Alicante de la Conselleria de Educaciò i Ciència.

Nos pusimos en contacto con el propietario de la finca quien nos informó de la actuación, a comienzos de la década de los 80 , de unos

\footnotetext{
${ }_{1}^{1}$ Agradecemos a D. Vicente Cerdán Cerón la información facilitada. También tenemos que agradecer a D. Luis Rico Gumiel, como propietario de la finca donde se ubican los restos, su colaboración y ayuda en todo momento para la realización de este trabajo.
} 
aficionados de la vecina localidad de Elche, que le pidieron permiso para excavar el lugar. No obstante, y tras enseñarle el dibujo de la planta realizado por nosotros, observó que así no había quedado antiguamente y que sin duda se había producido otra actuación incontrolada posterior. Para entonces, ya conocíamos la existencia de materiales recogidos del yacimiento y depositados en el Centro Cultural de la "Casa del Cisco", en Aspe. Al mismo tiempo, el Concejal de Cultura de la localidad estaba gestionando la incorporación de materiales de la primera actuación de los aficionados de Elche, tarea que dio sus frutos en septiembre de 1998.

En octubre de 1998 solicitamos el estudio de los materiales pertenecientes al yacimiento, procedentes de las dos actuaciones clandestinas, que ya se encontraban en la Colección Museográfica de Aspe. Tuvimos el acceso a dichos materiales en noviembre de 1999, tras la incorporación como director de la Colección Museográfica Municipal de Aspe de D. Francisco Javier Jover Maestre, a quien agradecemos su apoyo y las facilidades dadas para su estudio.

En definitiva, el yacimiento ha sufrido dos intervenciones que han exhumado totalmente la planta de un edificio y que han supuesto un daño irreversible a la investigación, con la destrucción de unidades estratigráficas y la pérdida de infor-

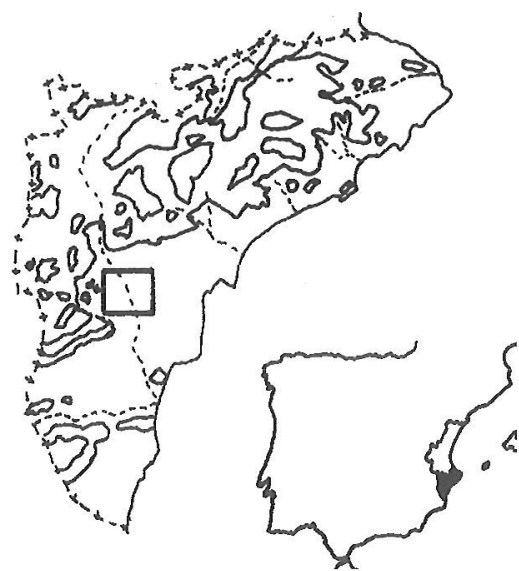

Figura 1: Mapa de localización.

mación referente a la localización exacta de los materiales arqueológicos dentro de la construcción.

\section{ENTORNO GEOGRÁFICO}

La sierra de Las Tres Hermanas (Lám. I) forma parte de las últimas estribaciones de las cordilleras béticas dentro de la provincia de Alicante, antes de entrar en la depresión de la Vega Baja. Situada en la cuenca meridional del valle medio del Vinalopó (Fig. 1), sigue una ensilladura transversal perteneciente a la fase subbética,

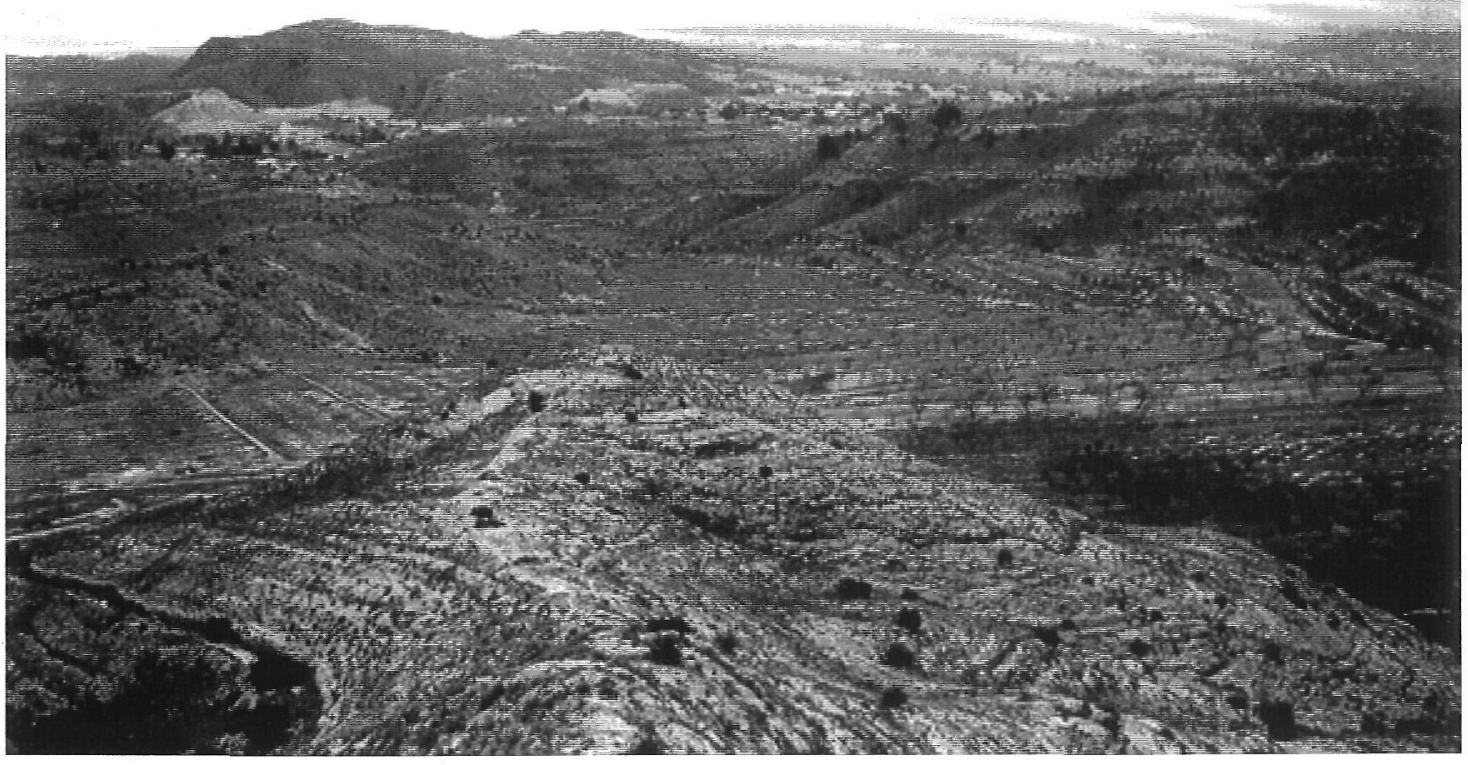

Lámina I: Vista del entorno del yacimiento hasta el litoral; en el centro, el edificio A. 
formada por tres picos alineados en dirección NNE-SSO, que continúan junto a las sierras del Azafá y del Castro, aunque separadas de éstas por los barrancos de la Fuente El Hermano y de Las Monjas.

El relieve está ligado al afloramiento del Trías de carácter Tortoniense, debido a un importante fenómeno diapírico. La presencia de glacis y depósitos cuaternarios es muy limitada en lo que respecta al entorno inmediato del yacimiento, en concreto por su solana, debido principalmente a los agentes erosivos, que han dejado al descubierto la secuencia estratigráfica predominante del Triásico representada por las calizas dolomíticas, margas y calizas tableadas, que aparecen entre los cortes de los cerros de forma horizontal y originando en ocasiones auténticas plataformas y alineaciones calizas. Desde el punto de vista tectónico-litológico se podría incluir dentro de las unidades post-manto, como un conjunto de materiales sedimentarios formados por margas, calizas y conglomerados detríticos, situados entre dos dominios diapíricos, al norte el diapiro de Agost y al sur el del Vinalopó, con depósitos miocenos afectados por estos procesos (PAVÍA y PRIETO, 1998).

El agua de arroyada ha modelado las vertientes de los tres cerros formado un sistema de cárcavas, gracias a la pendiente, que va disminuyendo hacia la depresión de Elche, y debido también a la capacidad de drenaje que supone la proximidad del barranco de las Monjas. En este sentido, la sierra de las Tres Hermanas está rodeada por una zona endorreica que, originada en la fuente El Hermano, transcurre hacia el barranco de las Monjas el cual se diluye al norte de la ciudad de Elche. Esta vertiente debió ser más importante en la antigüedad, ya que destaca su desproporcionado tamaño en relación con su capacidad hídrica, que en la actualidad aparece como pequeños embalsamientos acuíferos en las zonas más bajas.

En el presente, la sierra está dedicada a la caza especializada, aunque hasta hace muy poco tiempo se cultivaban las zonas más bajas de la misma con bancales de naranjos, almendros y otros frutales. Los suelos son de calidad mediabaja, formados por arcillas y margas, aunque en la umbría de la sierra se abren los ricos terrenos cuaternarios del Medio Vinalopó que hoy están dedicados a la uva de mesa.

En lo que respecta al paisaje vegetal nos encontramos en el piso termomediterráneo de clima semiárido, donde aparece el sistema degradado del Quercus Ilex - Pistacia Lentiscus, ahora representados por los tomillares y espartos
(Thymus vulgarys, Stipa tenacissima). El crecimiento de las especies arbóreas, como la coscoja (Quercus coccifera) y el pino carrasco, que en algunos puntos de la sierra aún perdura, se enfrenta a serios problemas derivados de la escasa cubierta donde mantenerse; sí aparecen otras formas vegetales como el palmito (Chamaerops humilis), el espino (Rhamus lycioides), la olivardina (Osyris quadripartita), la retama (Ephedra fragilis), el lentisco (Pistacia lentiscus), y las esparrageras (Asparagus albus y a. horridus). Estos datos caracterizan una zona ampliamente deforestada y que debió estar más ricamente poblada de especies arbóreas. En este sentido, los análisis antracológicos efectuados por E. Badal (BADAL, 1990) en el yacimiento de El Tabayá, correspondiente a la Edad del Bronce, muestran la presencia del fresno, especie que junto a muchas otras han desaparecido de estas zonas.

\section{EL YACIMIENTO}

\section{Situación}

El yacimiento de Las Tres Hermanas se encuentra situado a unos $2.700 \mathrm{~m}$ al sur del casco urbano de Aspe. Hoja de Elche, $n^{\circ} 28$ - 34 (871). Escala 1: 50.000 . Mapa Topográfico del Servicio Geográfico del Ejército. Coordenadas. U.T.M. 30 S XH 959443 (Fig. 2).

\section{Descripción}

Los tres cerros presentan cotas de 365,364 y 370 m s.n.m., unidos por lenguas a 351 y 344 $\mathrm{m}$. Desde el cerro central surge a modo de espolón una nueva elevación dirigida al sur con una cota máxima de $327 \mathrm{~m}$ en una pequeña planicie

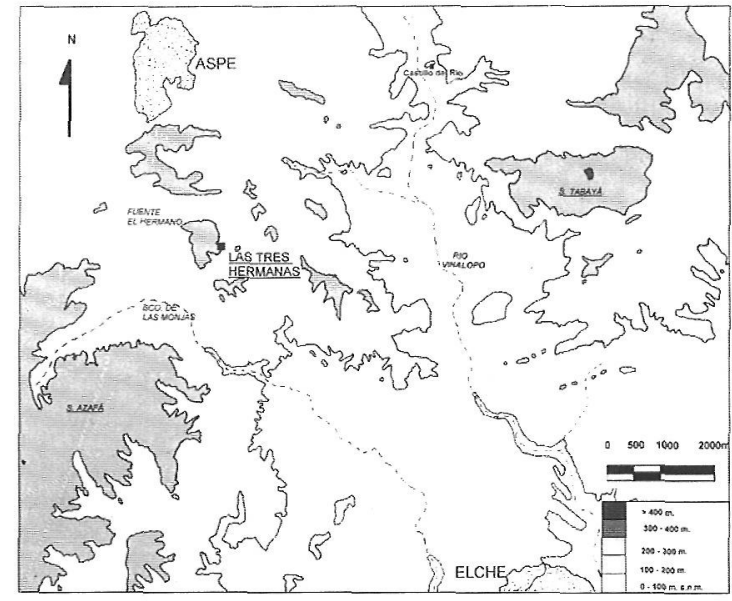

Figura 2: Mapa comarcal 
de unos $200 \mathrm{~m}^{2}$ de superficie, donde se encuentra la estructura "A" que describiremos posteriormente. Desde esta altura el campo visual del entorno es amplio excepto hacia el oeste donde el propio cerro de Las Tres Hermanas actúa de barrera, razón por la que hemos creido conveniente tomar los datos de visibilidad desde el vértice geodésico, por otro lado muy cercano al edificio objeto de estudio, además de que en este punto también se han localizado restos constructivos, tal vez ibéricos, de los que luego hablaremos.

Partiendo de esta premisa, el campo visual que se ofrece es, sencillamente, impresionante. Así, hacia el norte el panorama abarca todos los llanos cuaternarios que se localizan en torno a la cuenca media del río Vinalopó teniendo como límite la sierra de El Cid; en dirección nordeste se abre el corredor que conduce hacia Agost, y desde aquí hacia L'Alacantí. Por el este la visibilidad se ve limitada por una serie de cerros contiguos que impiden ver el río Vinalopó, no obstante la red caminera tradicional que pasa a levante del cerro se identifica con facilidad. Hacia el sudeste, de nuevo, la panorámica es muy amplia alcanzando, en primer término, la llanura del Baix Vinalopó y, en segundo lugar, todo el litoral que va desde la sierra de Santa Pola hasta la sierra de El Molar. En dirección sur y sudoeste volvemos a encontrar importantes obstáculos (sierra de la Azafá y sierra de Crevillent) que provocan un campo visual escaso o limitado. Por último, la visibilidad vuelve a ser amplia o muy amplia hacia el oeste (hasta la sierra de La Horna) y el noroeste (hasta la sierra de Betíes).

La extensión del yacimiento ocupa unos $6000 \mathrm{~m}^{2}$, y presentaba una gran cantidad de

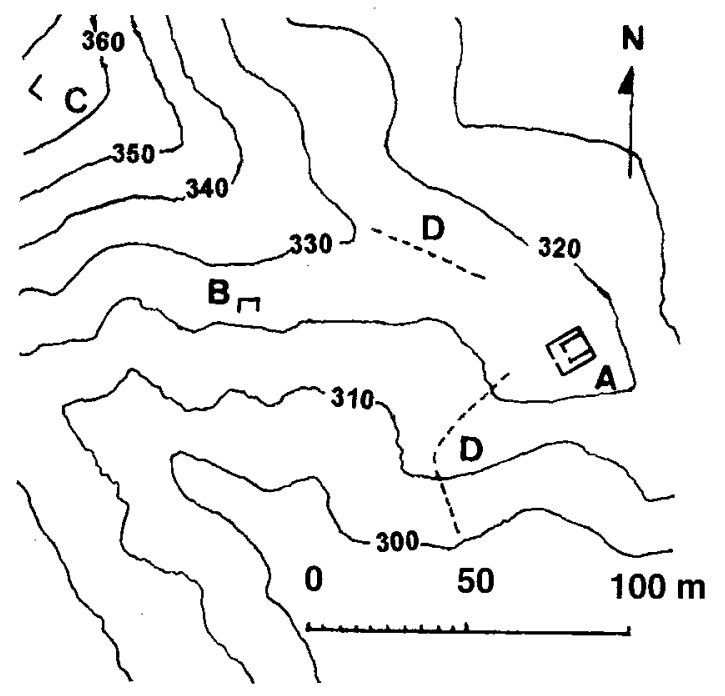

Figura 3: Sectores del asentamiento. restos cerámicos en superficie hasta hace algunas décadas (según información del propietario), aunque en estos momentos son escasos debido a los continuos saqueos que ha sufrido. En la actualidad, se observa cerámica de la Edad del Bronce, especialmente en el cerro más occidental, aunque pueden encontrarse fragmentos prácticamente en todas las laderas de la sierra. No existen estructuras visibles asociadas a esta etapa cultural, y el reducido inventario cerámico no ofrece datos suficientes para efectuar un análisis más detallado, teniéndolo que adscribir al II milenio a.n.e.

A diferencia del habitat en la Edad del Bronce, el asentamiento ibérico parece concentrarse en las laderas de la sierra y en la cima del cerro central.

\section{RESTOS CONSTRUCTIVOS}

En cuanto a las estructuras (Fig. 3), se han podido constatar varias alineaciones de muros en el cerro occidental, que no han sufrido ninguna intervención, y en la ladera del cerro central donde se pueden distinguir dos departamentos, uno sin excavar y otro parcialmente excavado en una actuación clandestina (Edificio $B$ ) donde se rebajó un relleno de unos $25 \mathrm{~cm}$. En la zona superior de la lengua central o antecerro, aparece una construcción totalmente excavada en una actuación similar (Edificio A), que es nuestro principal objeto de estudio, y por último, justo en el vértice geodésico del pico central, aparece otra construcción totalmente expoliada (Edificio C) .

\section{Edificio A (Fig. 4 y 5) (Lám. II y III)}

Se halla emplazado sobre la cima amesetada de lo que, en términos geográficos, denominaríamos antecerro, es decir, una pequeña elevación que a modo de espolón sobresale en dirección este-oeste de una alineación montañosa más alta que queda a poniente (el cerro de Las Tres Hermanas propiamente dicho). Esta pequeña plataforma alcanza una cota de $327 \mathrm{~m}$ s.n.m. siendo su desnivel respecto al nivel de base circundante de unos $50 \mathrm{~m}$. Ofrece un difícil acceso por todas sus vertientes, con pendientes alrededor del 35\%, a excepción de la ladera sudoeste donde la pendiente calculada es del $25 \%$.

Esta estructura, de la que ya hemos presentado un avance (GARCÍA y MORATALLA, 1999), ha sido excavada sin ningún tipo de rigor científico hasta sus cimientos, dejando en 


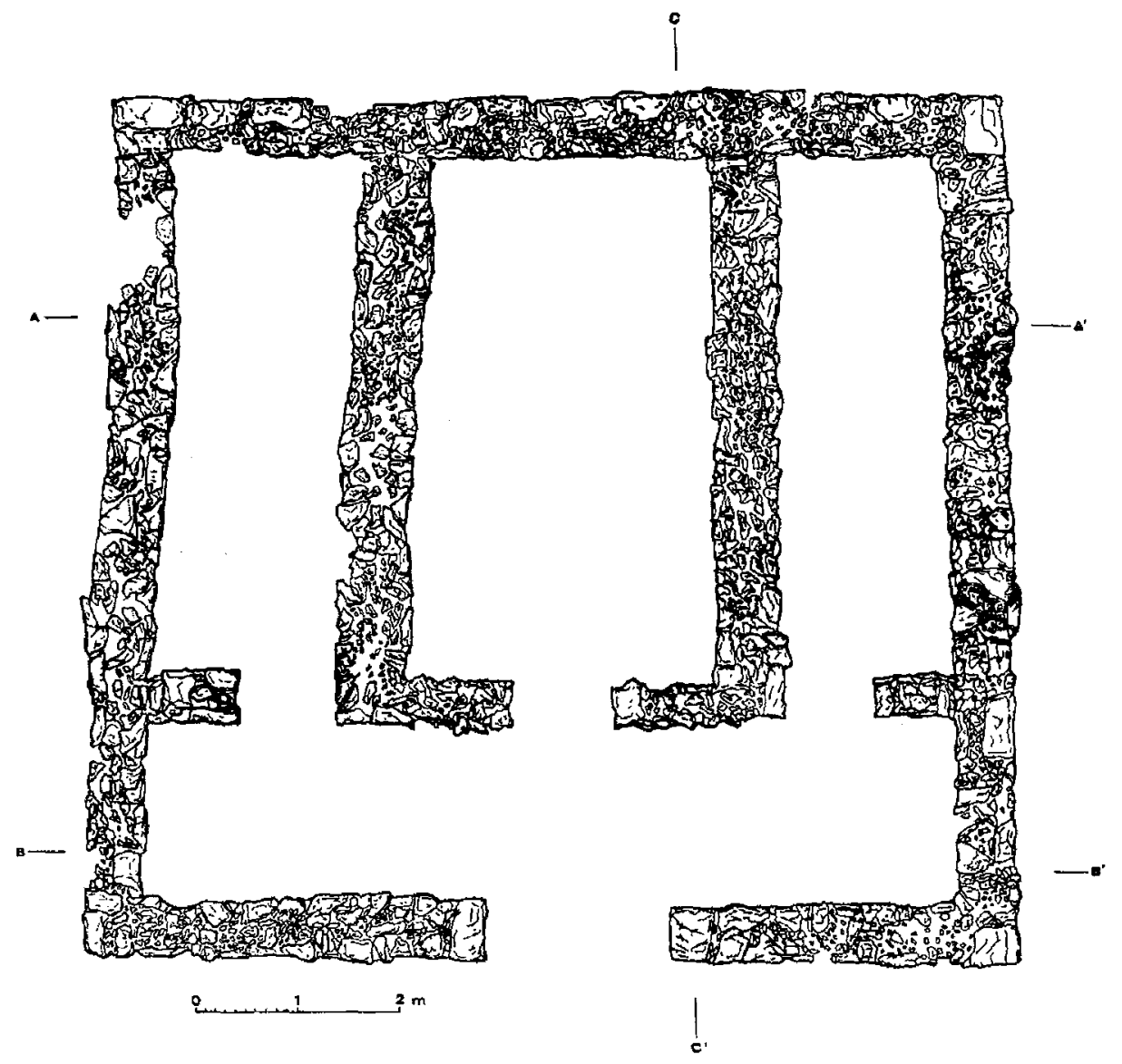

Figura 4: Planta del edificio A.

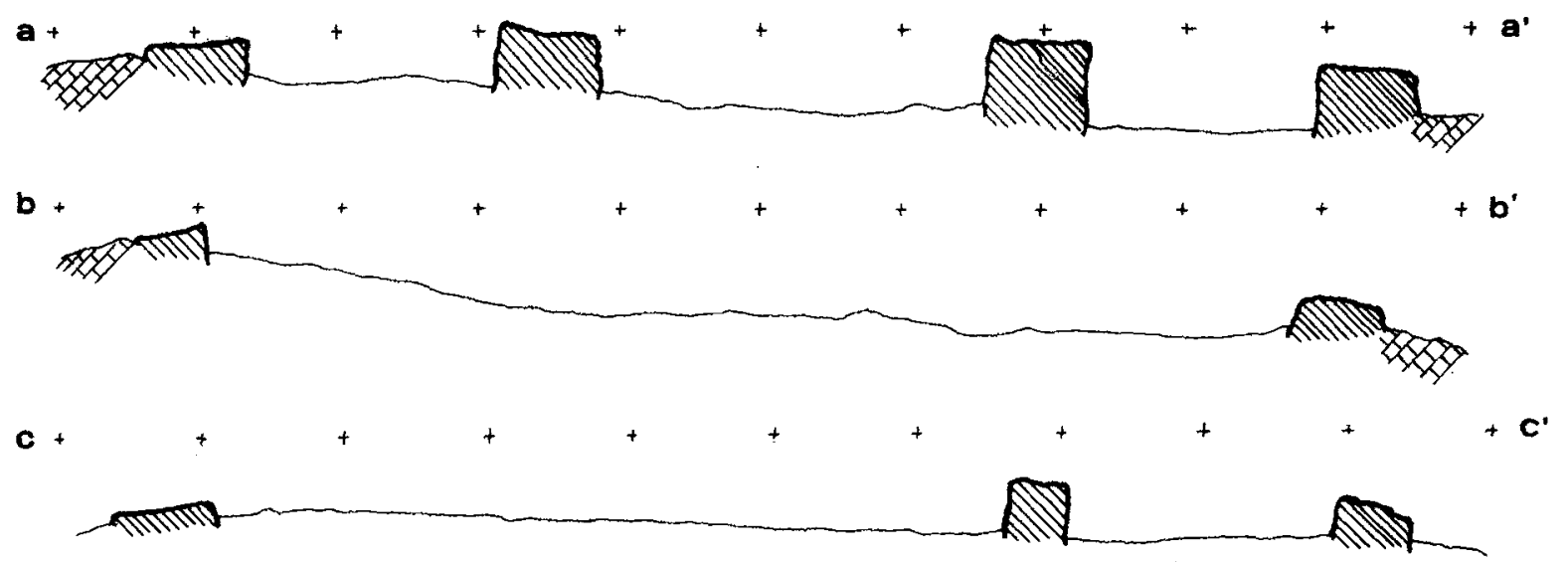

Figura 5: Secciones del edificio A.

superficie, al margen de los muros, una gruesa capa de arena suelta producto de tan desafortunada actuación. Por este motivo, la caracterización tanto técnica como arquitectónica de la construcción necesariamente será incompleta pues una gran cantidad de datos, que sería prolijo aquí enumerar, se han perdido, quizás para siempre ${ }^{2}$.
Los muros del edificio, y la planta que conforman, suponen el mejor objeto de análisis.

¿Es perfectamente posible una intervención arqueológica de urgencia sobre los restos, al menos para retirar el citado volumen de tierras sueltas, pero no nos atrevemos a asegurar que se obtengan resultados trascendentales; tal vez quede algún sector con restos de pavimento o enlucidos de las paredes, tal vez no quede sencillamente nada. 


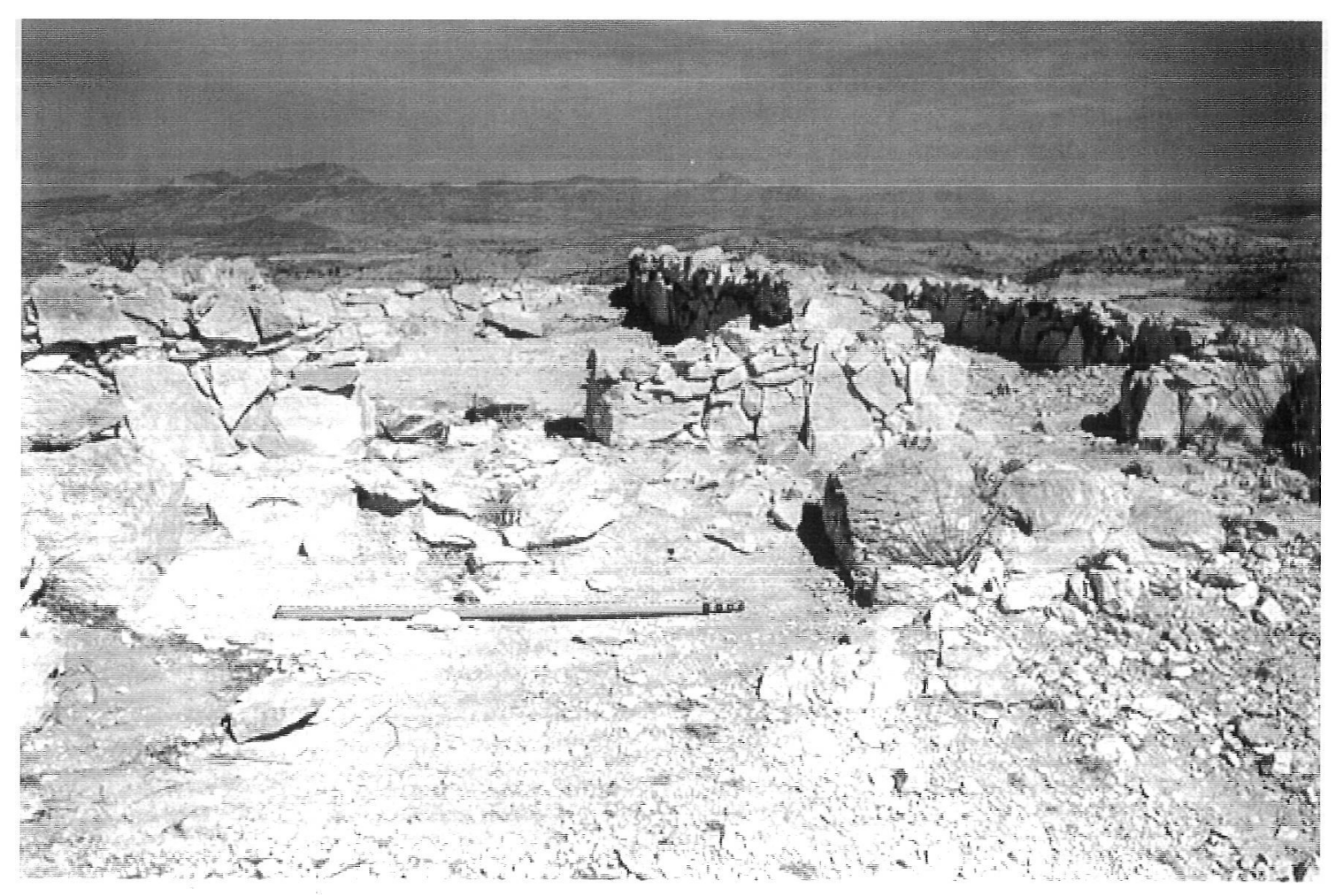

Lámina II: Detalle del edificio A.

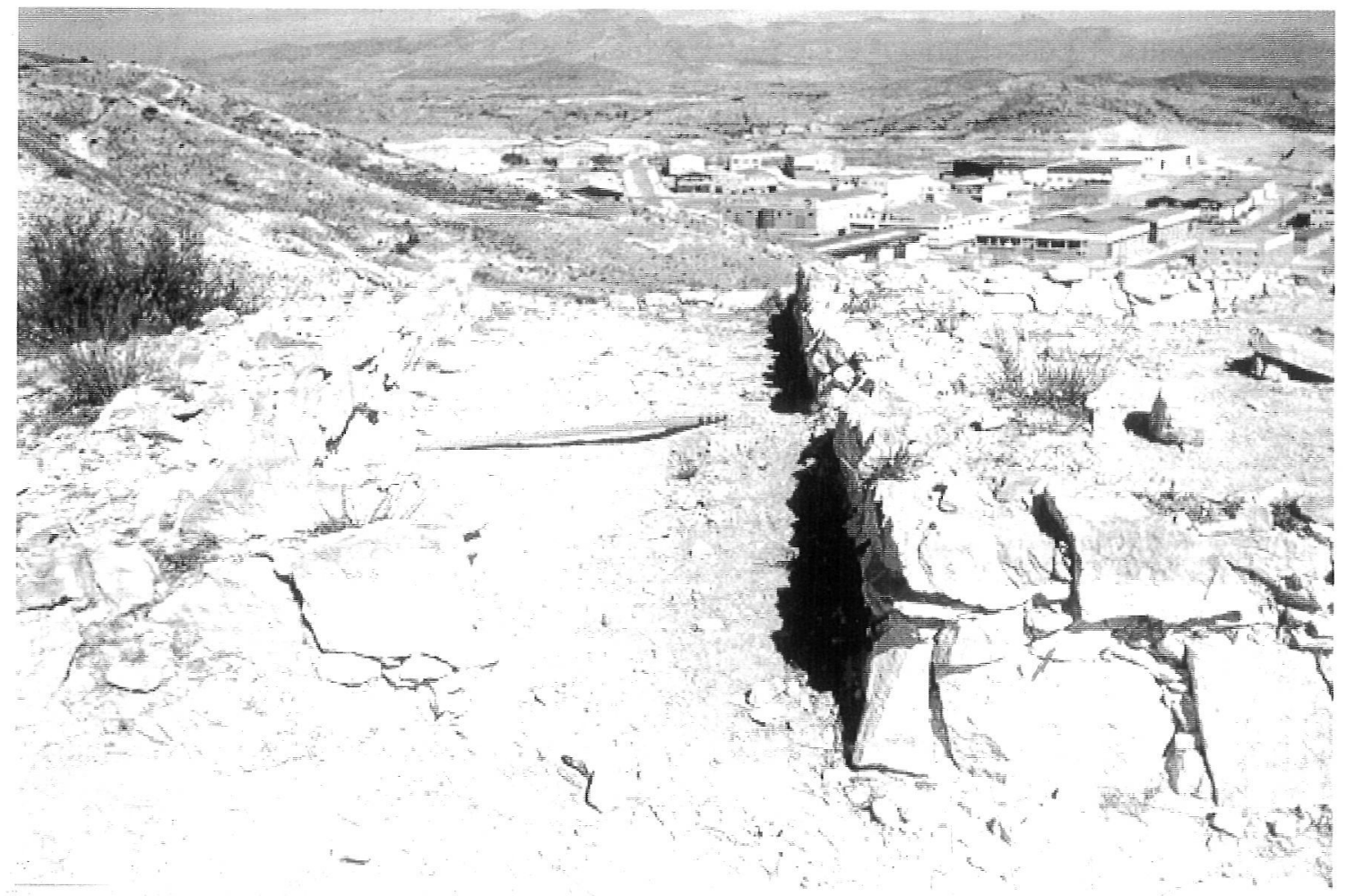

Lámina III: Detalle del edificio A. 
Se trata de una construcción prácticamente cuadrada (9'12 m x 8'92 $\left.\mathrm{m}=81^{\prime} 35 \mathrm{~m}^{2}\right)^{3}$, con un vano de 1'80 $\mathrm{m}$ abierto en mitad del muro meridional por el que se accede a una primera sala (pronaos), dispuesta en sentido este-oeste, a través de la cual la circulación se distribuye hacia tres salas paralelas en sentido norte-sur que configuran una característica cella tripartita. A la estancia occidental se accede por un vano de 0'88 m mientras que en la oriental alcanza hasta 0'92 m, y más aún, 0'96 m, en el vano que comunica con la nave central.

El proceso constructivo no es difícil de determinar pues la relación estratigráfica entre las estructuras muestra claramente que, en primer lugar, se levantan los muros perimetrales, con un ancho medio en torno a los $60 \mathrm{~cm}$; a continuación se realiza la división interna y en este punto merece la pena destacar una clara diferencia de módulo, pues mientras los muros con planta en $\mathrm{L}$ que delimitan la cella central mantienen la anchura citada, los que delimitan las cellae laterales de la pronaos disminuyen su calibre hasta 0'49 m. Tal vez, este hecho esconda una refacción en el edificio aunque esta información puede haber desaparecido para siempre, dada la intervención realizada. En este sentido la curvatura que muestra el muro perimetral oeste podría explicarse también como una refacción, circunstancia que se explicaría por el hecho de que en ese punto la roca natural aflora en cotas más elevadas, por lo que la estabilidad del edificio pudo verse comprometida.

Los paramentos se construyen con un doble lienzo de piedras calizas irregulares, sin duda traídas de muy cerca, y un relleno de casquijo, todo ello trabado con una argamasa de arena, trazas de cal y agua. En determinados puntos aparecen bloques de aspecto prismático y sillarejos bien trabajados, sobre todo en las esquinas, sirviendo de unión entre dos tramos, y delimitando las puertas, a modo de jambas. En el alzado (Fig. 6), que se conserva en más de 50 $\mathrm{cm}$ en algunos puntos, las hiladas parecen alternar el calibre: la primera muestra piedras de gran tamaño, las mayores de toda la construcción, luego aparecen otras más pequeñas para mostrar en la tercera hilada de nuevo bloques de tamaño grande o mediano. Se trata de una técnica constructiva bien documentada en poblados ibéricos, por ejemplo El Oral (ABAD y SALA, 1993), donde la hilada de piedras más pequeñas pretende regularizar la superficie de asiento de la siguiente. No hemos encontrado, obviamente, ninguna evidencia de adobes aunque puede ser de gran interés mencionar el hallazgo de una plaqueta rectangular de arcilla de tono ocre, aparentemente local; su reverso está alisado y en el anverso conserva dos listeles en resalte (Fig. 15). Se trata de una pieza que pudiera pertenecer a la decoración del edificio, tal vez a modo de friso corrido, dato que sería muy revelador sin duda pues probaría la singularidad de la construcción; de hecho, apenas hemos podido constatar la presencia de este posible elemento decorativo en la arquitectura ibérica, tan sólo su mención en alguna construcción de Ullastret y Ampurias, casos ciertamente particulares (MALUQUER et alii, 1986, 76).

Como ya hemos adelantado, toda la técnica constructiva responde a formas de trabajar indígenas y habría numerosos ejemplos al respecto aunque los paralelos más cercanos los encontramos en las estancias del citado poblado de El Oral, sobre todo la presencia de jambas en las puertas, los sillarejos en las esquinas o la alternancia de hiladas. Teniendo en cuenta la cronología de este yacimiento $\left(1^{a}\right.$ 1/2 del s. $V$ a.n.e.) y del de Las Tres Hermanas (entre fines del $V$ y fines del IV a.n.e), no resulta descabellado defender una tradición constructiva local cuyo origen habría que remontar al Periodo Orientalizante y que tiene en este edificio estudiado un singular ejemplo.

\footnotetext{
${ }^{3}$ Téngase en cuenta, a la hora de comparar las distintas medidas que ofreceremos que, ciertamente, estos datos no son del todo exactos pues desconocemos qué valores se alcanzarían teniendo en cuenta los distintos revestimientos que sin duda tuvieron estas estructuras.
}

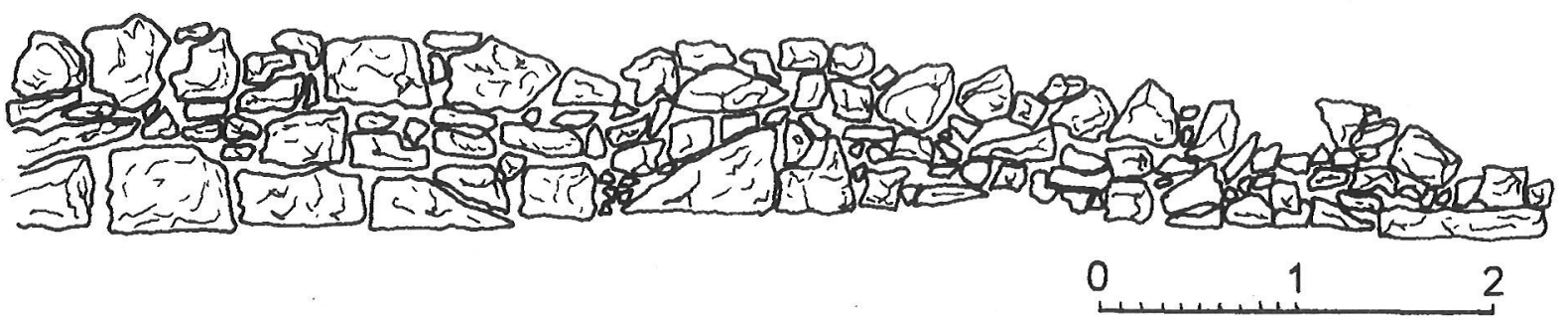

Figura 6: Alzado muro oeste de la estancia central. 


\begin{tabular}{l|ccccc} 
Tramo & Centímetros & Valor máx. pie & $\mathbf{N}^{\circ}$ de pies & Valor mín. pie & $\mathbf{N}^{\circ}$ de pies \\
\hline Muro 1 & 892 & 29,8 & 29,9 & 29,2 & 30,5 \\
Muro 2 & 908 & 29,8 & 30,5 & 29,2 & 31,1 \\
Muro 5 & 904 & 29,8 & 30,3 & 29,2 & 31,0 \\
& & & & & \\
Muro 3 & 356 & 29,8 & 11,9 & 29,2 & 12,2 \\
Muro 4 & 404 & 29,8 & 13,6 & 29,2 & 13,8 \\
Muro 6 & 596 & 29,8 & 20,0 & 29,2 & 20,4 \\
Muro 7 & 596 & 29,8 & 20,0 & 29,2 & 20,4 \\
Muro 8 & 180 & 29,8 & 6,0 & & \\
Muro 9 & 180 & 29,8 & 6,0 & 29,2 & 6,2 \\
& & & & & 29,2 \\
Muro 10 & 88 & 29,8 & 3,0 & 29,2 & 3,0 \\
Muro 11 & 88 & 29,8 & 3,0 & 29,2 & 3,0
\end{tabular}

Tabla 1. Módulos arquitectónicos.

En cuanto a su modulación, hemos podido comprobar el más que probable uso de un pie de 0’295 m. Así, los muros más anchos tendrían dos pies por uno y medio de los más estrechos; los vanos interiores responden a un módulo de tres pies mientras que el acceso principal justamente lo dobla (seis pies). Los muros maestros que delimitan el edificio tendrían 31 pies y las medidas vuelven a ofrecer datos convincentes en la distribución del espacio interno: la pronaos tiene 6 por $27^{\prime} 5$ pies, la estancia central $18^{\prime} 5$ por 10 pies y las laterales $18^{\prime} 5$ por $5^{\prime} 5$ pies.

Esta modulación no es nueva para la arquitectura ibérica, ni tampoco exclusiva. Un experto en la materia como M. Almagro-Gorbea, a propósito del estudio del monumento de Pozo Moro (ALMAGRO-GORBEA, 1983, 211-213), constata el empleo de este módulo a lo largo y ancho de toda la cuenca del Mediterráneo y en distintas culturas del I Milenio a.n.e. Parece que nos encontramos ante unas constantes metrológicas ampliamente difundidas y asimiladas a modo de koinè por diferentes pueblos desde la época Orientalizante, y el ibero fue uno más. A este respecto, merece la pena traer a colación el reciente estudio sobre metrología realizado en el yacimiento de La Picola (MORET y BADIE, 1998) contemporáneo a nuestro edificio y muy cercano en el espacio, en Santa Pola (Alicante). En este asentamiento se vuelve a constatar esta modulación en la construcción del poblado llegando estos autores a propugnar la intervención de arquitectos extranjeros en su planificación, sobre todo en la fortificación, y en cualquier caso probando la estrecha relación de la cultura ibérica con las corrientes mediterráneas de los siglos V y IV a.n.e.

A nuestro juicio, es indudable que el edificio que mayores afinidades guarda con el nuestro de Las Tres Hermanas es el denominado "Templo
A" de L'llleta dels Banyets, en El Campello (LLOBREGAT, 1988), paralelismo que se ve reforzado por su proximidad tanto en el espacio, unos $35 \mathrm{Km}$ en línea de aire, como en el tiempo pues serían contemporáneos.

Existen algunas diferencias arquitectónicas que no podemos obviar, como son la presencia de un acceso con columnas in antis en la construcción de L'Illeta, la división de la nave central en su parte zaguera creando dos estancias a modo de opistódomo o su planta rectangular. Pero al margen de estos hechos, que pueden explicarse por la mayor majestuosidad del edificio campellero, el concepto arquitectónico es el mismo, es decir, una construcción que tras el acceso presenta una estancia a modo de pronaos muy poco profunda a partir de la cual la circulación se distribuye hacia una gran cella tripartita siendo la central más ancha que las laterales. Es un esquema que también se identifica claramente en construcciones tan singulares como el sepulcro de Toya o el palacio de Cancho Roano (ALMAGRO-GORBEA y DOMINGUEZ DE LA CONCHA, 1988-89). A propósito de este último, ambos autores defienden, con profusión de ejemplos, un origen de la planta en las casas de bit-hilani del norte de Siria. El bagaje intelectual de estos investigadores y los paralelos por ellos citados nos exime de profundizar en la cuestión por lo que remitimos a estos trabajos para quien quisiera profundizar en estos temas.

\section{Edificio B (Fig. 7)}

Este edificio se localiza en la ladera occidental de la lengua que une el antecerro con la cota central de la sierra de Las Tres Hermanas. En este tramo, las afloraciones calizas permiten un ligero allanamiento horizontal, a modo de 


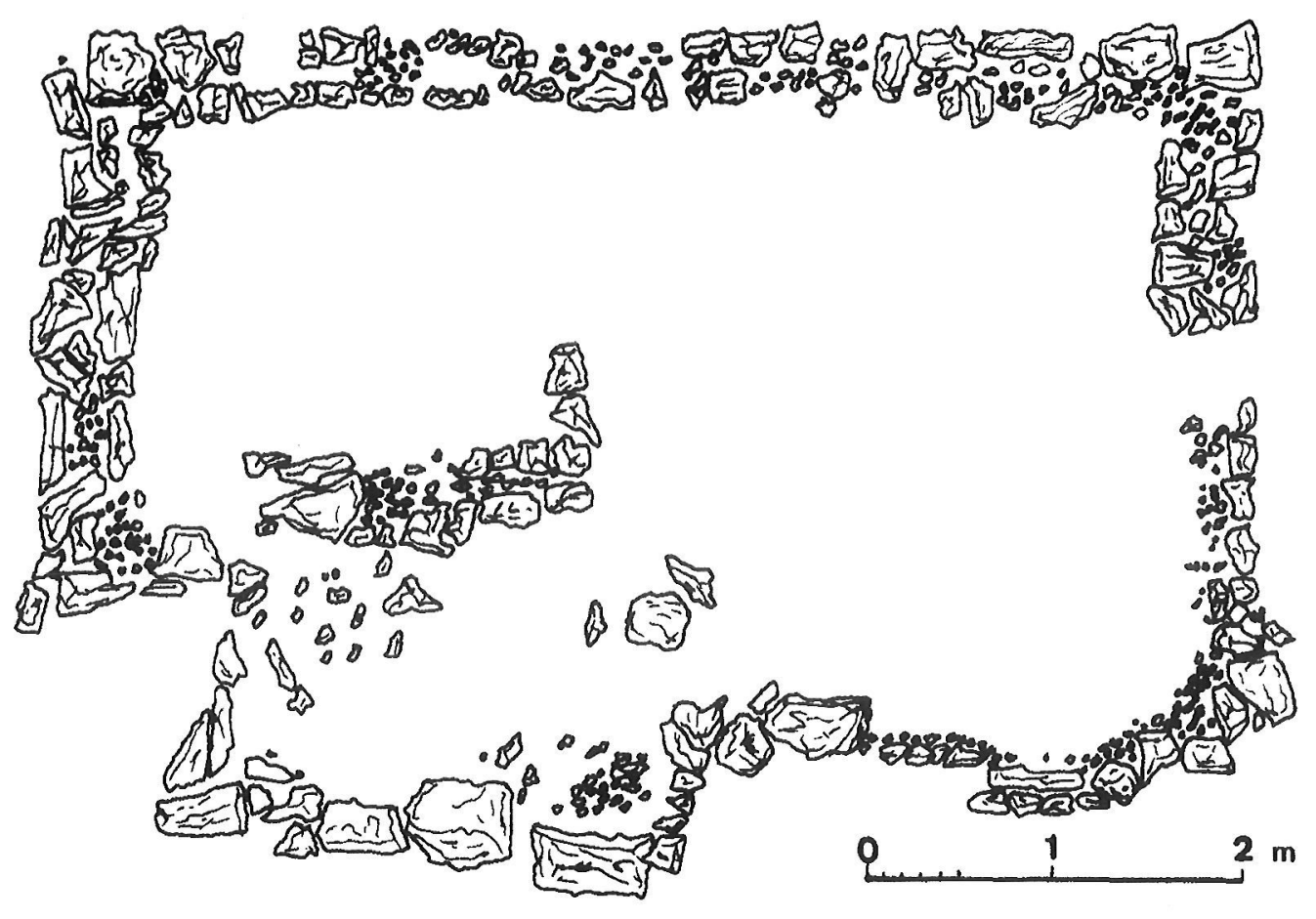

Figura 7: Planta del edificio B.

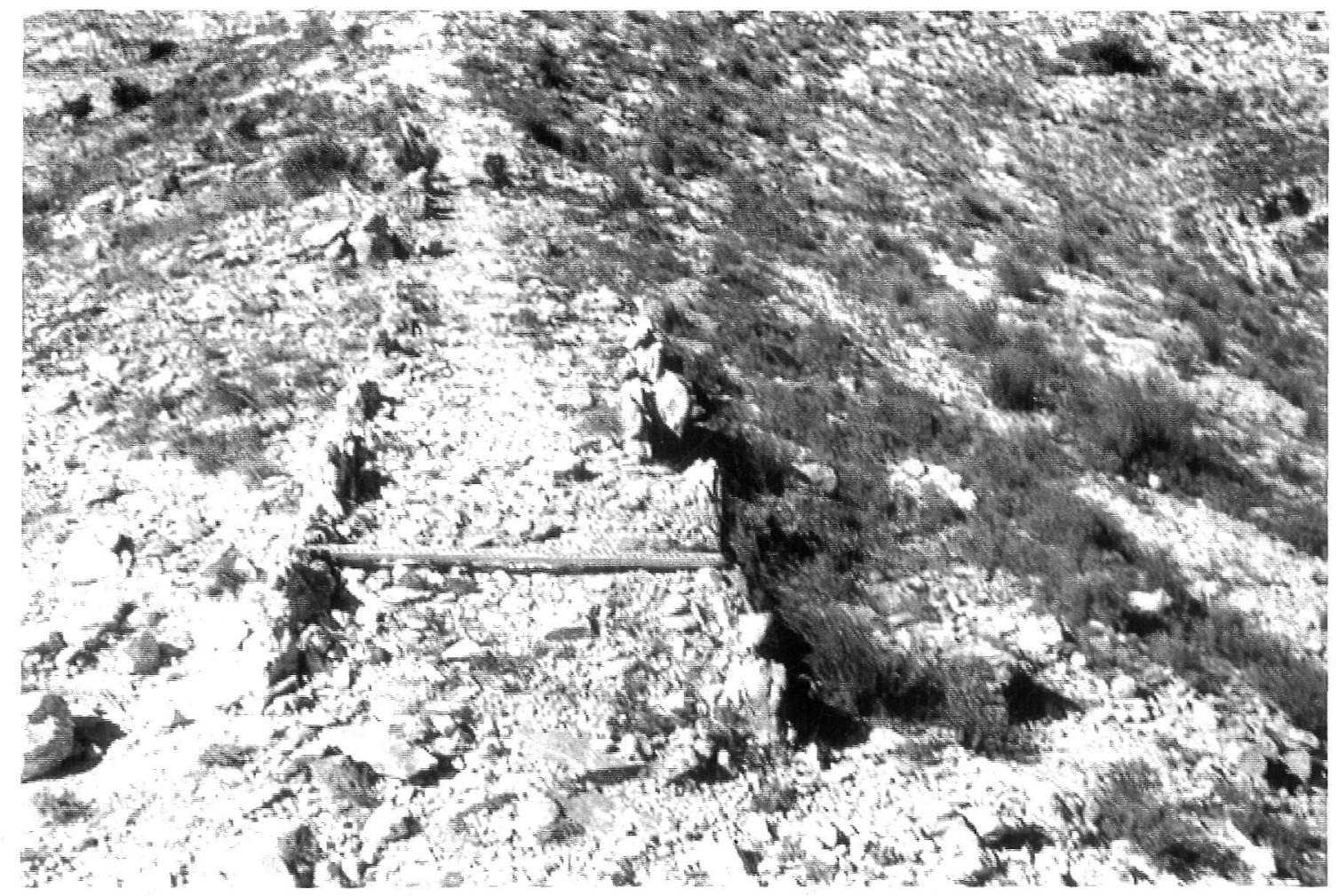


plataformas sobre una pendiente más acusada, donde se distribuyen algunos departamentos. EI denominado Edificio $B$ ha sido parcialmente excavado en una actuación clandestina, aunque las hileras de los muros que no han sido excavados son visibles perfectamente debido sobre todo al nivel de arrasamiento que ha sufrido por la erosión.

El edificio presenta una planta rectangular: $6,40 \times 3,96 \mathrm{~m}$ miden los muros norte y este respectivamente mientras el muro oeste tiene $3,23 \mathrm{~m}$, pues deja una esquina libre con una especie de plataforma aparentemente adosada al muro sur. En el espacio interior se observan algunas alineaciones de piedras que podrían corresponder a estructuras.

La técnica constructiva de los muros, en principio, es similar a la del edificio anterior aunque el esquema constructivo es más sencillo, en cuanto a la división del espacio interno, y sus medidas son menores; del mismo modo, la hipotética presencia de una plataforma que asoma al desnivel de la vertiente oeste confiere al edificio cierta peculiaridad. Sobre la modulación, no parece prudente realizar ningún cálculo mientras no se realice una intervención científica que documente su planta con seguridad.

En sus alrededores aparecen algunos fragmentos cerámicos, probablemente desestimados durante el proceso de expoliación, básicamente galbos de cerámicas comunes sin decoración ni formas dibujables.

\section{Edificio C}

En una de las cotas más altas de la sierra, en la cúspide del cerro central, se encuentra una estructura exhumada probablemente durante la primera actuación. Se trata de una alineación de piedras de gran tamaño toscamente trabajadas, con una anchura media de $0,40 \mathrm{~m}$, que se sitúan formando una estancia de tendencia circular de unos tres metros de diámetro. Únicamente queda la primera hilada de esta estructura que bien podría tener una funcionalidad de vigía gracias a su excelente visibilidad. Se han observado materiales arqueológicos en sus alrededores tanto de la Edad del Bronce como ibéricos, lo que no nos permite aventurar su adscripción cronológica a una u otra etapa.

\section{Estructura D (Lám. IV)}

Se ha constatado, además, en este yacimiento una estructura de la que no hemos encontrado paralelos en la arquitectura me- diterránea, por más que hemos repasado las síntesis al uso. Se trata de una construcción formada por dos hileras paralelas de piedras planas, en su mayoría de tamaño mediano, hincadas verticalmente y separadas ambas entre 0,90 y $1,10 \mathrm{~m}$; en algunos puntos ambas líneas están unidas por otra transversal a modo de escalón, lo que le da un aspecto de estrecho camino. Se localiza en la ladera occidental del antecerro donde se encuentra el Edificio A, ascendiendo justo por donde la pendiente es menor y describiendo una curva abierta; su trayecto no es continuo pues la roca natural aflora en algunos puntos perdiéndose su pista. Su recorrido aproximado es de unos $50 \mathrm{~m}$ dirigiéndose sin duda hacia el edificio principal que definimos como regia. Aparece de nuevo con las mismas características en la lengua que une el antecerro con la cota central y se encamina, prácticamente en línea recta, hacia el Edificio $C$, perdiéndose donde aflora de nuevo la roca, con una longitud adicional aproximada de unos 20 metros.

A modo de hipótesis podemos plantear que se trate de un acceso, una senda que se dirige hacia el edificio principal pero su uso concreto se nos escapa, fundamentalmente debido al sesgo en el que se encuentra la información del yacimiento y a no haber encontrado ningún paralelo que puedan aportar alguna pista. En cualquier caso, su propia construcción ya es digna de reseñar dado el esfuerzo añadido que ello requiere.

\section{EL REPERTORIO CERÁMICO}

Los materiales que se han podido catalogar proceden de tres fuentes. En primer lugar los materiales recogidos en las tareas propias de prospección, escasos aunque significativos, contemplados en las signaturas $\mathrm{TH} / 98-1, \mathrm{TH} / 98-2$, $\mathrm{TH} / 98-3, \mathrm{TH} / 99-28, \mathrm{TH} / 99-29, \mathrm{TH} / 99-30, \mathrm{TH} /$ 99- 31, TH/99- 32, TH/99- 33 y TH/99- 34. En segundo lugar, la referida entrada en el Museo Arqueológico Provincial del Alicante, representada con las signaturas $\mathrm{TH} / 99-(\mathrm{n})$; y por otra, los fondos expuestos y depositados en la Colección Museográfica de Aspe, signados con THe/99-(n). En esta colección se encuentran, además, piezas signadas producto de la primera actuación en el yacimiento, con la abreviatura $\mathrm{TH}-1-(n)$.

Es difícil realizar una contextualización de las piezas dado que desconocemos la procedencia exacta de los materiales, aunque las piezas enteras y sin huellas de líquenes deben 
pertenecer a los espacios expoliados. Sólo 10 fragmentos han sido recogidos en las tareas propias de prospección, y tan sólo uno, el fragmento de elemento constructivo $(\mathrm{TH} / 98-3)$, está relacionado directamente con el edificio pues se halló en la terrera del mismo; los demás materiales han sido recogidos en diversos sectores del yacimiento: laderas, Edifico B, Edificio C y Estructura D.

\section{Cerámica de importación (Fig. 8,1-4)}

La cerámica ática representa probablemente el mejor exponente de la vajilla de lujo dentro del repertorio cerámico del poblado, si bien es cierto que las piezas no son espectaculares ni en número ni en calidad. Únicamente disponemos de 3 fragmentos de borde (Fig. 8, 1-3) y el fragmento de una base (Fig. 8,4 ), representando el $4,5 \%$ de total inventariado. Los bordes han podido clasificarse con seguridad como dos kylix "tipo inset - lip", Ilamados comúnmente "copa Cástulo" (TH/99 -33 y THe/99 - 7), y una de las páteras de la forma Lamboglia 21 (TH/99 - 32), semejante a algunos ejemplares del Ágora de Atenas de la primera mitad del siglo IV a.n.e. (SPARKES y TALCOOTT, 1970). Son formas relativamente comunes en yacimientos contestanos, como la L'llleta dels Banyets (OLCINA, 1997) y El Puntal de Salinas (HERNÁNDEZ y SALA, 1996). En cuanto a los fragmentos de la copa Cástulo, hay que indicar que estas piezas suelen aparecer en contextos del último tercio del siglo $V$ a.n.e., sin embargo en este caso muestran un distinto aspecto técnico: el borde no es muy exvasado, sino más bien rectilíneo; además, el labio tiende a ser redondeado en lugar de apuntado y sus paredes son mucho más finas, lo que le da un aspecto más frágil. La pasta también es diferente, siendo en este caso de color anaranjado, de textura no muy dura, y el barniz es de peor calidad. Estos caracteres nos indicarían que estamos ante series con una cronología de mediados del siglo IV a.n.e., con paralelos también en el Puntal de Salinas ${ }^{4}$. Respecto a la base de cerámica ática, no podemos precisar la forma concreta, aunque el estudio de la pasta y de la calidad del barniz nos sitúa en una cronología similar a las piezas anteriores.

Es interesante destacar un fragmento de un probable mortero púnico (TH/99-34) (Fig. 8, $5)$, identificado gracias a los desgrasantes de tono oscuro y plateado, comunes en estas cerámicas (RAMÓN, 1991), que viene a reforzar la adscripción cultural de este yacimiento dentro del Ibérico Pleno.

\section{Cerámica Ibérica}

La tipología seguida para el estudio de la cerámica correspondiente al período ibérico ha sido la propuesta por L. Abad y F. Sala (ABAD y SALA, 1995).
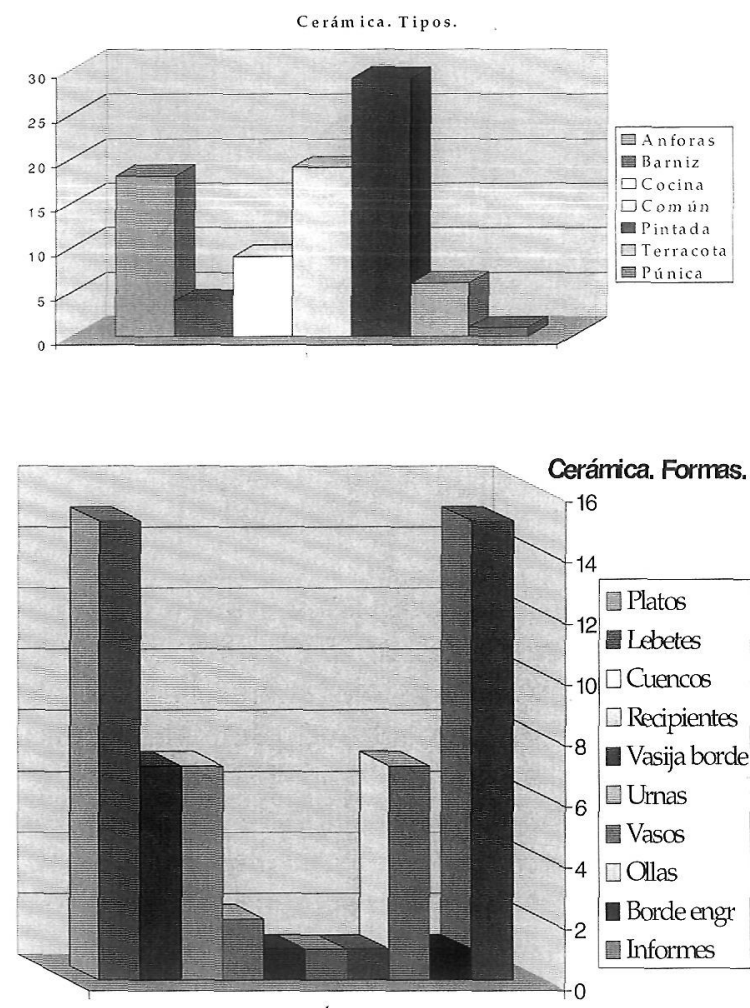

Anforas (Fig. 9).

Se han identificado un total de 13 piezas correspondientes a ánforas, lo que representa un $19,6 \%$ del total de la cerámica inventariada. Son bordes variados que por lo general pertenecen a los tipos habituales de ánforas ibéricas definidas por Ribera (RIBERA, 1982) y constatadas en yacimientos ibéricos contemporáneos cuyo mejor paralelo sigue siendo el yacimiento de El Puntal de Salinas donde se han registrado un buen repertorio de ánforas (HERNÁNDEZ y SALA, 1996).

No obstante, se pueden distinguir tres tipos atendiendo a las características de las pastas cerámicas: por un lado las producciones locales,

\footnotetext{
${ }^{4}$ Agradecemos la información sobre esta pieza a la doctora F. Sala Sellés.
} 

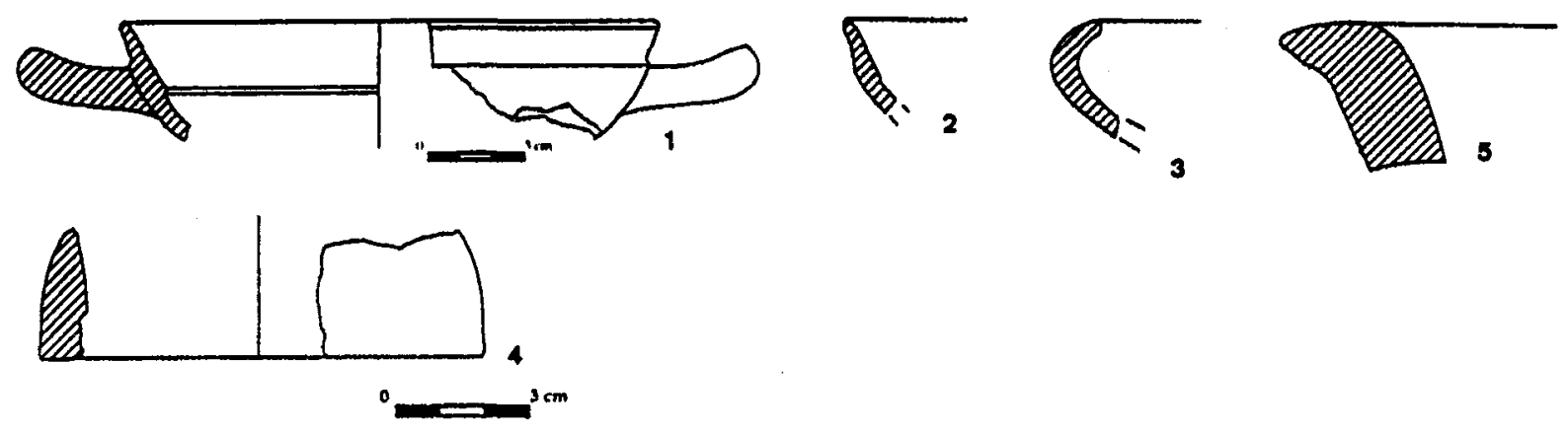

Figura 8: Cerámica de importación.
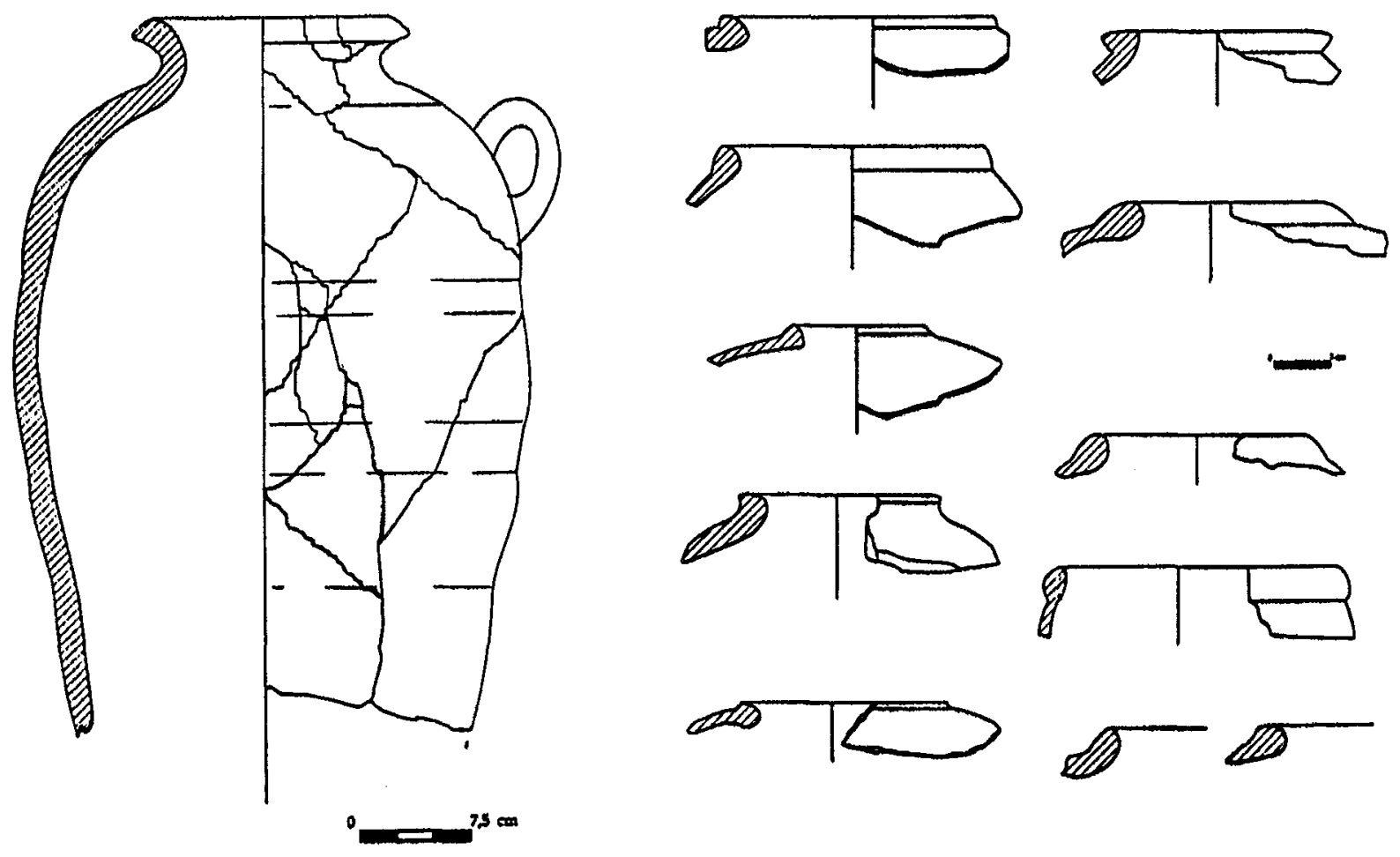

Figura 9: Ánforas.
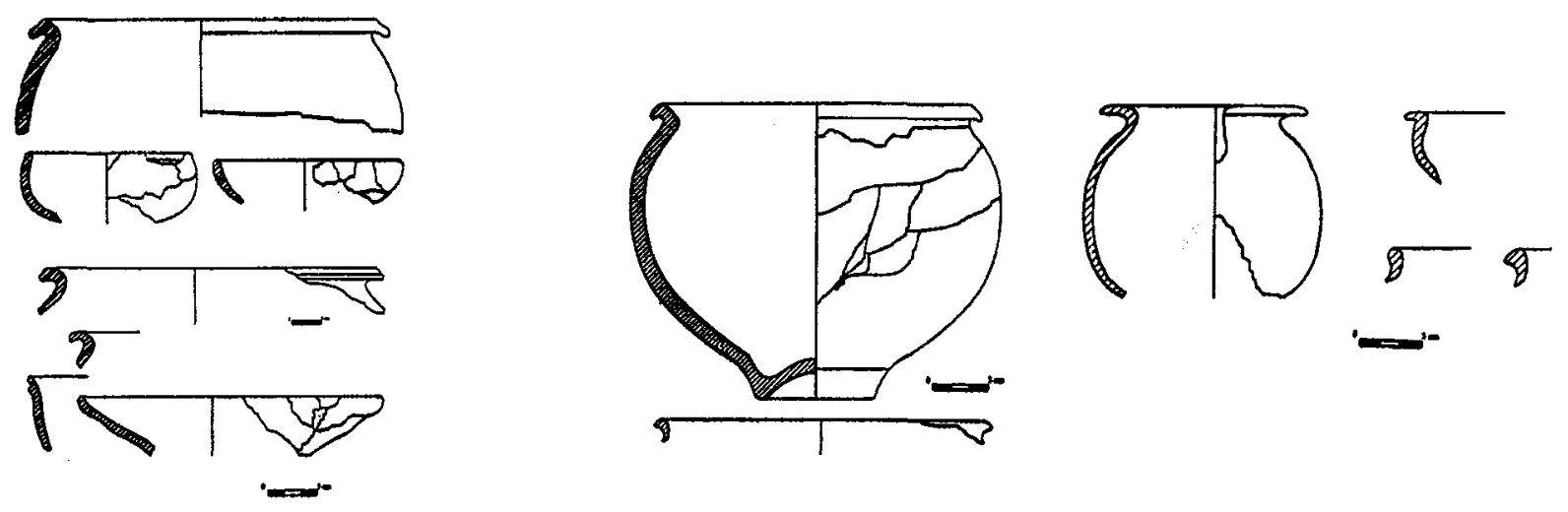

Figura 10: Cerámica común.

Figura 11: Cerámica de cocina. 
fácilmente identificables por su similitud con la pasta de la cerámica común; probablemente ha sido confeccionada con la arcilla del Keuper que aflora en diversos puntos de la cercana cuenca del Vinalopó, utilizando como desgrasante elementos calcáreos de tamaño medio, con predominio de trazas blancas y granas, en una cocción oxidante que les proporciona un aspecto anaranjado. En segundo lugar, encontramos otros fragmentos con una composición distinta, donde los elementos calcáreos son sustituidos por otros de tamaño más reducido y de color oscuro y que incluso incorporan trazas de cuarcita; este grupo lo podríamos incluir dentro del conjunto de ánforas ibéricas no locales, entendiendo por tales aquéllas que no proceden de un radio inmediato al asentamiento. Por último, se ha podido diferenciar por su tipología un borde de un ánfora del Estrecho (TH/99-5), del tipo Mañá-Pascual A3, también con una cronología entre fines del $\mathrm{V}$ y mediados del s. IV a.n.e. (RODERO, 1991), recipiente que aunque reducido en número aporta un dato importante sobre la capacidad de relación comercial de este asentamiento. Se trata de un fragmento de pasta de color rojo y superficie idéntica, con desgrasantes calizos blancos y trazas tanto negras como plateadas.

\section{Cerámica Común (Fig. 10)}

La cerámica común representa un 27,2\% de las piezas inventariadas. Este grupo corresponde a una cerámica de pasta bien depurada, buena cocción que alterna la oxidante y reductora, dando el típico aspecto sandwich, y un acabado cuidado generalmente con un engobe beige claro.

Entre los tipos destacan claramente las formas abiertas, donde platos y cuencos representan más de la mitad del inventario, y los lebetes, hasta las tres cuartas partes del mismo.

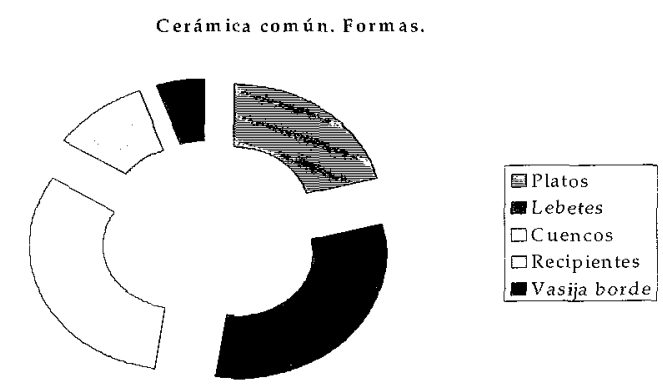

Cerámica de Cocina (Fig. 11)

La cerámica que hemos denominado de cocina $(13,6 \%)$ corresponde a la realizada mediante cocción reductora con abundante desgrasante de origen calcáreo y tamaño mediano-grueso, numerosas vacuolas y con acabado alisado. Estas piezas estarían destinadas a la cocción de alimentos, pues se observan en varios ejemplares las señales del fuego. Dentro de las formas advertimos un total predominio de las ollas donde podemos distinguir entre el subtipo mediano y el pequeño. Las ollas medianas tienen entre 21 y $25 \mathrm{~cm}$ de diámetro de borde y unos $25 \mathrm{~cm}$ de altura, mientras que las pequeñas no sobrepasan los $15 \mathrm{~cm}$ de diámetro de borde y su altura se establece entre los $12-15 \mathrm{~cm}$.

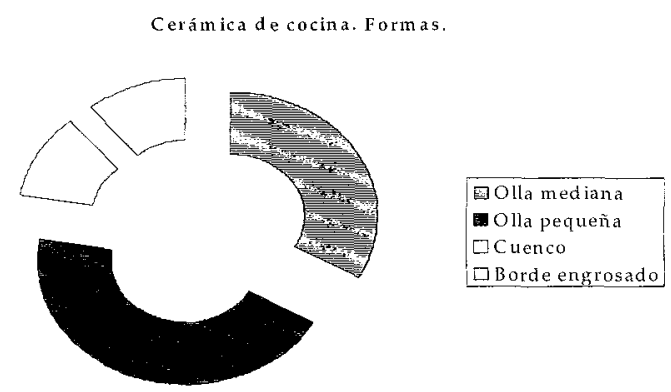

Cerámica Pintada (Figs. 12 y 13)

La cerámica pintada representa un $25,7 \%$ del total de tipos inventariados, aunque es bien cierto que esto puede deberse a las características de esta colección, ya que en estos casos se recogen principalmente los fragmentos decorados. Esta circunstancia queda constatada por el gran número de fragmentos informes con relación a otras piezas. Las formas predominantes siguen siendo las abiertas con platos, cuencos y lebetes, aunque no descartamos la presencia de otros tipos que se pueden intuir entre los fragmentos de panza, probablemente de grandes contenedores, pithoi o tinajas.

Dentro de la decoración predominan los motivos pintados rectilíneos simples, formando bandas y filetes, y círculos concéntricos completos o seccionados por la mitad. Aparecen otros motivos ondulados de orientación vertical: las denominadas "melenas o cabelleras", diseñando entre todos variadas composiciones. En algún caso se ha observado la presencia de algún fitomorfo, en concreto un fragmento con un roleo (THe/99-14). Este motivo pudiera alargar la cronología final del asentamiento hasta fines del IV o incluso ya el s. III a.n.e., pues este tipo de decoraciones son, con los datos que hoy tenemos, prácticamente inexistentes en contextos ibéricos contestanos del s. IV a.n.e.

El color de estos motivos varía entre las diversas gamas producidas por la presión o la 

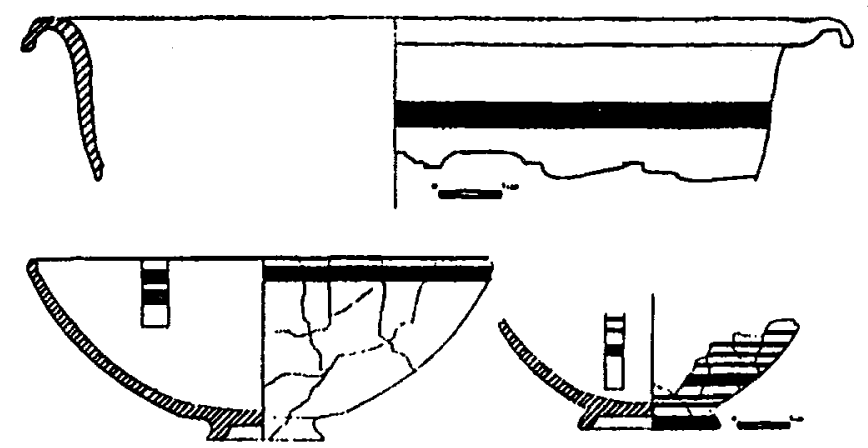

Figura 12: Cerámica pintada.
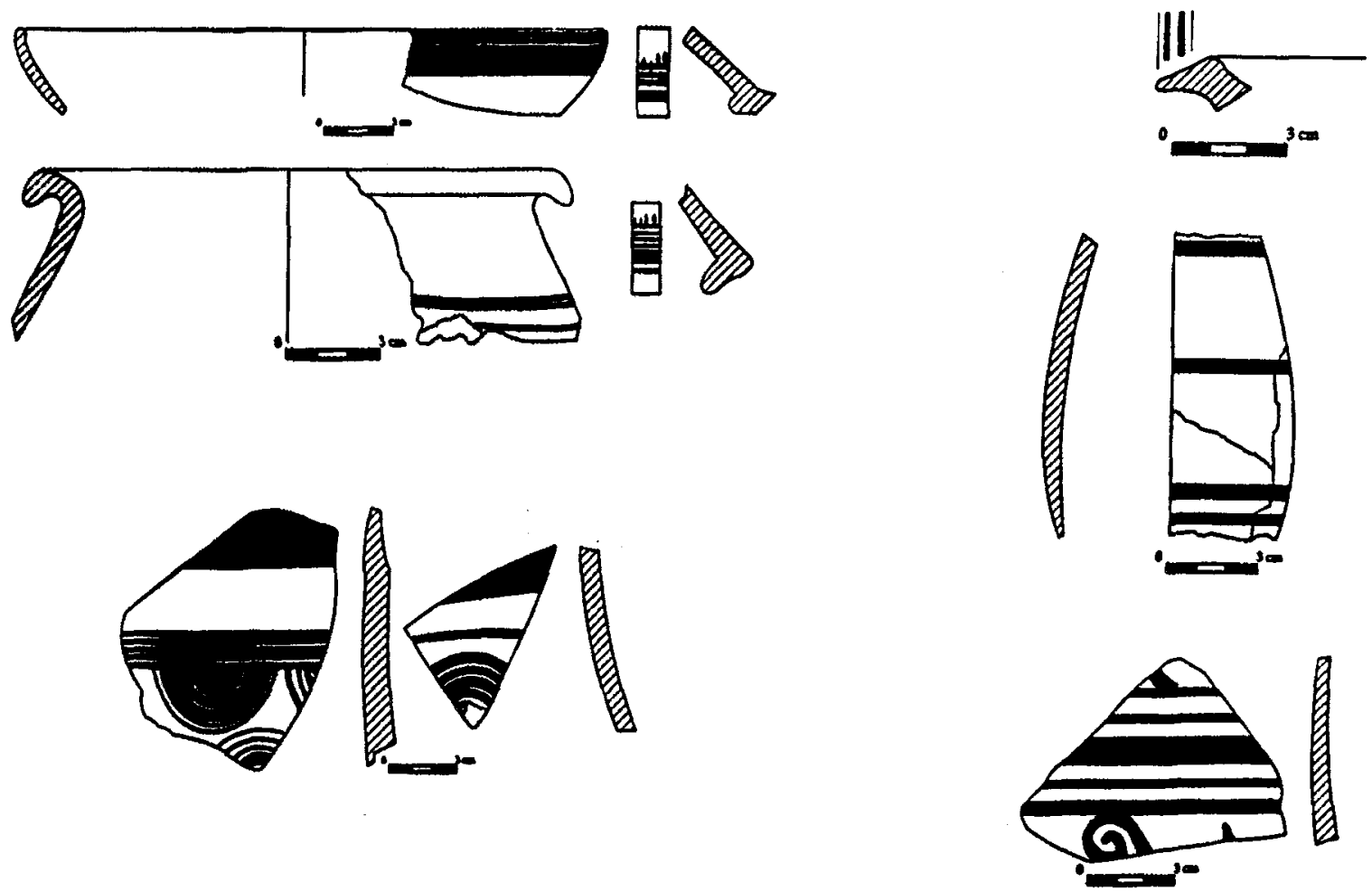

Figura 13: Cerámica pintada.
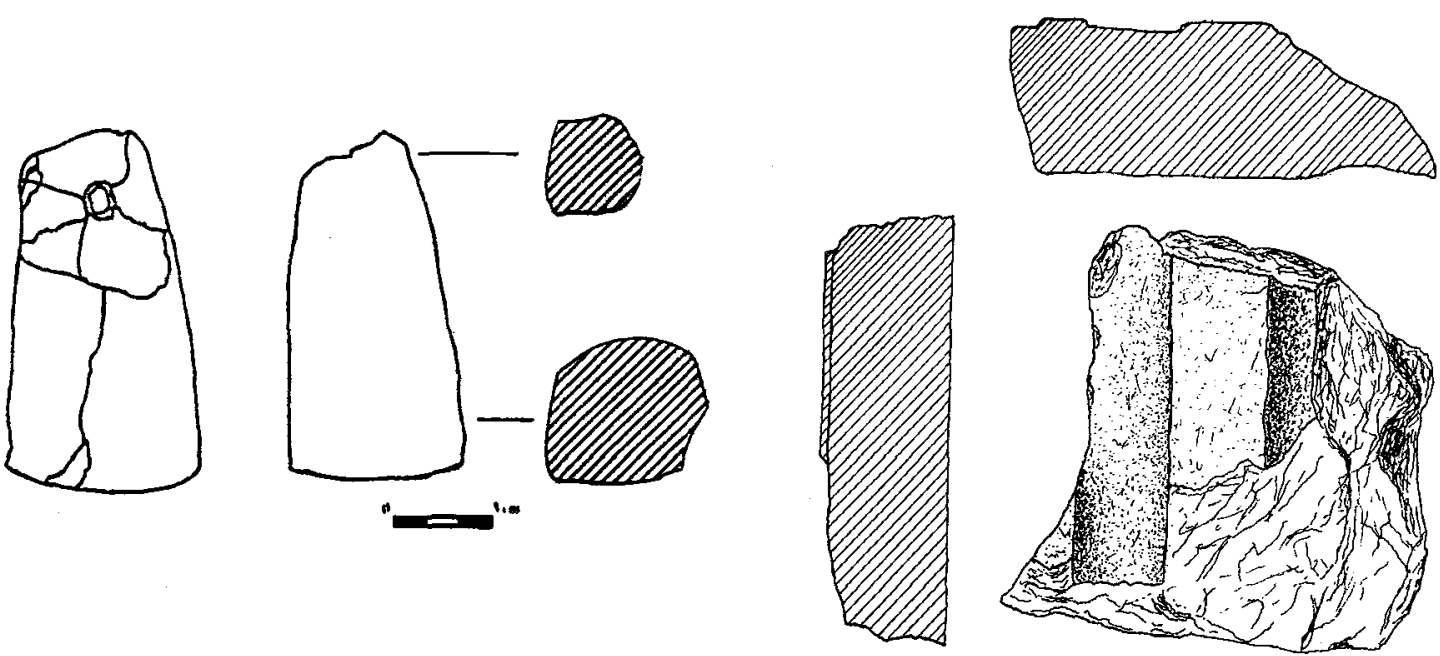

Figura 14: Pesa de telar.

Figura 15: Moldura de terracota. 
cantidad de una tonalidad del rojo vinoso, si bien es cierto que existen trazos en negro, gris, y otros de un matiz claro entre el anaranjado y el castaño.

Cerámica pintada. Formas.

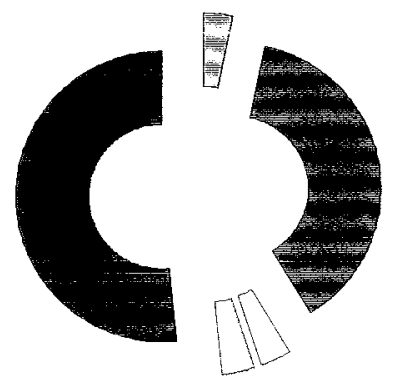

$\square$ Lebetes

曾Platos

$\square$ Urnas

$\square$ Vasos

Intormes

\section{OTROS MATERIALES}

\section{Objetos de terracota}

Dentro de los objetos de terracota incluimos las piezas que han sido preparadas con barros decantados y posteriormente cocidas pero que no pertenecen a la vajilla doméstica. En particular, se han inventariado cinco pesas de telar (Fig. 14), halladas con el Edificio A según nos han relatado aficionados locales. Estos pondera tipológicamente son semejantes a los registrados en otros poblados contemporáneos.

La presencia de un posible elemento de decoración encontrado en la terrera del edificio excavado (Fig. 15), del que no se han encontrado paralelos, ilustra la excepcionalidad de la construcción hallada. Este tipo de elementos recuerda la decoración metopada de los templos griegos o etruscos aunque la escasez de paralelos peninsulares nos impide entrar en otras valoraciones. De ser cierta nuestra hipótesis, nos encontraríamos ante un ejemplo de integración cultural en el Mediterráneo de gran valor en unas fechas, hacia mediados del siglo IV a.n.e., que muestran un creciente Helenismo. En cualquier caso, el hecho en sí es bastante significativo dentro de la singularidad que caracteriza el edificio y avala, como otros datos constructivos, el interés por parte de la comunidad local de resaltar su aspecto exterior.

\section{Metales}

El número de piezas de metal encontradas en el yacimiento es escaso y reducido en cuanto al tamaño de los fragmentos pero su más que segura definición aporta una sugerente hipótesis que nos vuelve a recordar el paralelismo del edificio "A" con Cancho Roano y sus hallazgos pues las tres piezas de hierro representan una panoplia militar básica mientras que el fragmento de plomo, junto al hallazgo de una bola de galena, nos induce a sugerir la existencia de procesos metalúrgicos ligados a este asentamiento.

El primer fragmento de hierro (Fig. 16, 1) corresponde a la hoja de una falcata. Se trata de una lámina bastante exfoliada que conserva una longitud de 12 ' $6 \mathrm{~cm}$ con una ligera curvatura de sus lados generando una parte interna cóncava donde se ubica el filo cortante de la hoja; en el lado opuesto la lámina alcanza un grosor de 1'1 $\mathrm{cm}$. Esta morfología junto al característico filo interno ayuda a definir el objeto como un fragmento de falcata pues dentro del repertorio tipológico del utillaje de hierro ibérico no se encuentra útil alguno que pudiera responder a este tipo.

La segunda pieza (Fig. 16, 2) consiste en una lámina de hierro, bien conservada y arrollada formando un cilindro perfecto; por su cara interna y junto a uno de sus extremos conserva dos pequeños remaches que garantizarían una correcta sujeción con un probable astil de madera. Su longitud sería de 6 ' $8 \mathrm{~cm}$ mientras que el diámetro del cilindro generado sería de $11^{\prime} 5 \mathrm{~cm}$. Este tipo de regatones son poco corrientes en el utillaje ibérico y sólo encontramos esta técnica de trabajar el hierro para realizar instrumental muy específico, como los legones o pequeños escardillos (MORATALLA, 1994), o bien para enastar en una vara de madera, sirviéndole de contrapeso, colocando en el extremo opuesto una punta de lanza. Sobre la base de las medidas establecidas optamos por definirlo como un regatón de lanza pues el instrumental agrario mencionado siempre presenta cilindros mucho más grandes.

Por último tendríamos una pequeña punta de hierro (Fig. 16, 3) de apenas 4' $3 \mathrm{~cm}$ de longitud conservada y un diámetro medio de 0 ' $85 \mathrm{~cm}$. La fragmentación por su extremo superior nos informa sobre una longitud mayor, aunque resulte imposible calcularla, siendo su definición igualmente complicada. De nuevo acudiendo a los tipos metálicos en hierro podemos llegar a la conclusión de que probablemente nos encontremos ante un fragmento de soliferreum pues a pesar de su semejanza con una punta de clavo hemos de descartar esta relación dado que estos objetos son sensiblemente más delgados en cuanto a su grosor e incluso más cortos que la 
longitud que se puede inferir del fragmento que aquí tratamos.

Por lo tanto, podemos concluir que nos encontramos ante los restos de un conjunto armamentístico compuesto por una falcata, una lanza y una jabalina o soliferreum lo cual incide nuevamente sobre el carácter funcional del edificio, descartando su uso específico como espacio religioso y señalando su ocupación probable por parte de un miembro de la jerarquía militar, al menos como una de sus atribuciones, que tanto relaciona este edificio con la construcción y la cultura material exhumada en Cancho Roano.

Para finalizar esta exposición falta comentar el hallazgo de una lámina de plomo de 0 '77 cm de grosor y 0'90 gr de peso (Fig. 16, 4); es pequeña y algo retorcida, con huellas inequívocas de haber sido objeto de varias
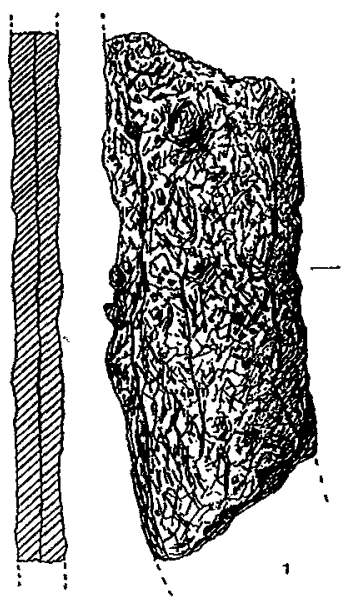
som
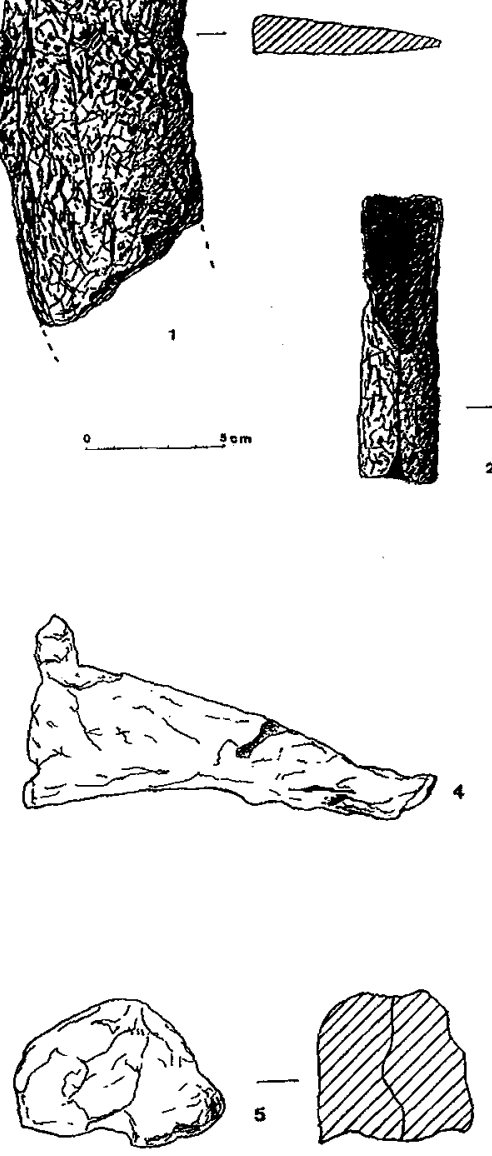

Figura 16: Metales. muescas aunque no acertamos a concretar su uso específico. Y por último, una pequeña bola de galena (Fig. 16, 5) de 0'73 gr de peso; al corte, ya realizado cuando nosotros la encontramos, se puede apreciar un núcleo brillante de color plateado rodeado de una delgada corteza de cerusita blanquecina de alrededor de 0 ' $1 \mathrm{~cm}$ de grosor; las vetas conocidas más cercanas de dicho mineral se localizan en la sierra de Callosa. Ante la posibilidad de que se tratara de una galena de tipo argentífero, la pieza fue sometida a analítica por microscopía electrónica dando por resultado una composición media del $85 \%$ de plomo y $15 \%$ de azufre, descartando por tanto la hipótesis referida. Se trata de una pieza que no ha sufrido ningún tipo de manipulación aunque desconocemos su aplicación concreta.

\section{CONCLUSIONES}

\section{Funcionalidad del edificio: ¿templo o regia?}

Como ya señalamos, los restos exhumados del Edificio A se localizan sobre una pequeña plataforma que se proyecta desde la sierra hacia la vaguada cuaternaria. Junto a él discurre la sugestiva estructura $D$ y además desde esta ubicación se domina el estrecho paso natural que conecta el Medio Vinalopó con su cuenca baja, ya en dirección hacia Elche. No existe a priori ninguna otra construcción en este lugar concreto por lo que se puede inferir la voluntad de mantener en una posición preeminente y aislada la planta de dicho edificio.

El resto de estructuras localizadas aparecen a unos 30-40 $\mathrm{m}$ hacia el sudoeste, en plena ladera (Edificio B), así como otras más alejadas en el vértice geodésico central (Edificio C). Es de presumir que las primeras sean departamentos ibéricos (no olvidemos que por la sierra también aparece material de la Edad del Bronce), dada su planta angular, la técnica edilicia y el registro material que aparece por sus alrededores. Resulta interesante constatar las diferencias constructivas entre este departamento B y el edificio A, fundamentalmente las proporciones y el uso de los sillarejos en las esquinas y en los vanos, a modo de jambas. Podemos llegar a la conclusión de que hay una clara voluntad de otorgar majestuosidad al edificio $A$, tanto por los cánones arquitectónicos como por su posición dominante sobre el entorno y ello aboga por una destacada

${ }^{5}$ Nuestro más sincero agradecimiento a César Doménech, geólogo, por el dictamen que nos ofreció. 
funcionalidad para esta construcción que parece razonable relacionar con las esferas políticas y/o religiosas de la comunidad que la ha erigido. Francamente la información sobre el urbanismo ibérico aún es escasa y no son muchas las plantas de poblados a las que podamos acudir en busca de referencias pero las singularidades arquitectónicas y constructivas relatadas así como su localización dentro del asentamiento nos permiten avanzar esta hipótesis.

En este punto y dados los paralelos conceptuales más cercanos nos enfrentamos ante la inevitable controversia entre su definición como templo o como regia, entendiendo por tal la residencia de una destacada autoridad de la comunidad, pues otras posibilidades hoy por hoy se nos escapan. Desde el principio manifestamos nuestra inclinación por la segunda función. La planta del edificio en poco se parece a los centros de culto fehacientemente identificados para el periodo Ibérico Clásico (MONEO, 1995) y por otro lado, el material arqueológico estudiado, muy escaso eso sí, tampoco demuestra prácticas religiosas inequívocas. Así, no tenemos constancia, ni siquiera oral, del hallazgo de terracotas o exvotos, omnipresentes en todo recinto sacro, $u$ otro tipo de productos como bronces o cerámicas singulares que nos permitieran suponer ceremonias relacionados con rituales religiosos. Muy por el contrario, el repertorio estudiado se compone de restos de ánforas ibéricas, con presencia de recipientes del área del Estrecho, platos, lebetes y pithoi pintados, platos comunes, ollas de cocina, un posible mortero púnico y las piezas áticas, dos copas Cástulo y un bol Lamb. 21. En cualquier caso, los hallazgos muestran ajuares bastante cotidianos donde conviven las necesidades de almacenamiento con las de consumo. A ello podríamos añadir la existencia de una panoplia militar básica así como la posibilidad de rastrear actividades metalúrgicas, teniendo en cuenta la presencia de la galena.

A pesar de la prudencia con que abordamos esta cuestión, dado el sesgo que tenemos en la información, tenemos la impresión de estar ante un edificio "civil", o que al menos no tuvo una función exclusivamente religiosa. Su concepción y los materiales conocidos responden mejor a la noción de regia definida por AlmagroGorbea y Domínguez (ALMAGRO GORBEA y DOMINGUEZ DE LA CONCHA, 1988-89), es decir, un edificio que fuera residencia de la jefatura del poblado, cualquiera que fuera la naturaleza de ésta, muy en la línea del palacio de Cancho Roano pero algo más sencillo. Por ello suponemos que dentro del esquema de la construcción tendrían cabida distintos usos según la estancia analizada, que nos es imposible definir dada la nula información que tenemos sobre la distribución de las piezas en el interior del recinto, y en los que tal vez no faltara un espacio para las prácticas rituales.

Con este planteamiento, y retomando el mejor paralelo que hemos encontrado para el Edificio A de Las Tres Hermanas, o sea, el Templo A de L'llleta dels Banyets, seguimos la hipótesis sugerida por ambos autores (op. cit., 366) que identifican esta construcción de El Campello como una regia, similar en concepción al palacio de Cancho Roano; en similares términos se han manifestado otros investigadores como $\mathrm{L}$. Abad y M. Bendala (ABAD y BENDALA, 1989, 58-60). Además de los paralelos arquitectónicos, se señala la semejanza tipológica del registro arqueológico (ánforas, jarras y platos pintados, ollas de cocina, alguna pieza de barniz negro ático, un mortero, el armamento...) y obviamente no podemos evitar constatar que este registro, por escaso que sea, es también el que se localiza en Las Tres Hermanas, por lo que nos encontraríamos ante un dato más que apoyaría su definición como regia. Probablemente la majestuosidad del edificio campellero así como el hallazgo de un fragmento de cabeza masculina esculpida en piedra inclinó a Llobregat a definirlo como un lugar sacro pero la verificación de la existencia de casas con plantas similares en el área sirio-palestina, así como la inexistencia de objetos suntuarios o exvotos apoya más su definición como lugares de residencia, seguramente de élites del poblado, que como espacios exclusivamente religiosos. Sin duda una excavación en extensión del asentamiento de Aspe, y de otros de su entorno inmediato, nos permitiría calibrar mejor la naturaleza de esta jefatura así como precisar hasta qué punto existe división de poderes entre lo sagrado y lo profano.

\section{El edificio en su espacio y su tiempo}

A nuestro juicio, los datos fundamentales que definen el papel de este asentamiento ibérico dentro del poblamiento comarcal, junto con la entidad del edificio, son los relativos a las variables de visibilidad y comunicación.

Se conjugan aquí un extenso control visual que incluye el Medio y Bajo Vinalopó, hasta el litoral, junto al control directo de una de las rutas tradicionales que comunica ambas comarcas. Es, por tanto, un hito clave dentro de este trayecto, al menos durante el siglo IV a.n.e, y cobra 
especial sentido teniendo en cuanta la relevancia del poblamiento ibérico a uno y otro lado de la alineación Sierra de Crevillent - Sierra del Tabayá.

En la solana se desarrolla un extenso y suave glacis, salpicado de zonas endorreicas en su contacto con el mar y con excelentes perspectivas agrarias; aquí (MORATALLA, 1999) la alta densidad del poblamiento parece determinada por el factor de atracción de un foco principal que debe ser La Alcudia, en principio el oppidum que regula el modelo de poblamiento en estas comarcas litorales, con su zona portuaria La Picola. Por otro lado, la ubicación de determinados asentamientos junto a las vías de comunicación con el interior pone de manifiesto el uso de estas rutas en el s. IV a.n.e.: El Castellar y El Forat en la sierra de Crevillent, La Moleta, siguiendo el río Vinalopó, por donde discurrirá la posterior Vía Augusta según algunos autores (MOROTE, 1979; ARASA y ROSSELLÓ, 1995), y ahora también Las Tres Hermanas, situado en medio de los anteriores. En la umbría, tierras de igual riqueza, destacan los hallazgos funerarios, con varios monumentos del tipo pilar-estela (ALMAGRO-GORBEA y RAMOS, 1986; ABAD et alii, 1995-97) en torno a las partidas de El Campet y Agualejas, en las terrazas cuaternarias del río Vinalopó. Además, es notorio constatar otros asentamientos en la salida hacia el valle medio de las rutas antes citadas: El Tolomó, junto a la vía que desciende de la Sierra de Crevillente, y Castillo del Río, siguiendo el curso del Vinalopó ${ }^{.}$.

Son dos áreas de un destacado poblamiento que tal vez participen en la integración de un territorio más amplio que se continúa hacia el norte, en paralelo al río Vinalopó (POVEDA, 1996; GRAU y MORATALLA, 1998), hacia tierras meseteñas. Existen afinidades materiales ya desde época orientalizante que resultan obvias en la fase clásica de la Cultura Ibérica (por ejemplo, entre la estatuaria de Monforte del Cid y la de La Alcudia) y que mostrarían estrechos vínculos entre los distintos sectores de poblamiento, pero es difícil probar una identidad a mayor nivel, plenamente política. Cada núcleo puede tener un control directo del entorno inmediato, y la distribución de los relieves sin duda ayuda a delimitarlo, pero también es posible que entre todos se reconociera una dirección política única. De hecho, si nuestra hipótesis fuera correcta, la existencia de la regia implicaría al menos el reconocimiento de dos unidades políticas diferenciadas $y$, a pesar de que la compartimentación del espacio físico no invalida esta dualidad, lo cierto es que no estamos en condiciones de definir el nivel de integración política de ambas, si es que lo hubo. En última instancia, se trata de dilucidar el radio de acción política de un oppidum que, a priori, se manifiesta como el principal núcleo urbano ibérico de las comarcas centro-meridionales de Alicante: $\mathrm{La}$ Alcudia. Pero, hoy por hoy, este nivel es imposible de alcanzar sin el estudio de las fases ibéricas de este emblemático yacimiento.

La regia de Las Tres Hermanas constataría la afirmación de una autoridad local y esto nos conduciría a defender una autonomía mínima para la misma en un territorio restringido al sur por las sierras Subbéticas y hacia el norte hasta la cuenca alta del río, donde de nuevo puede repetirse el choque de intereses, esta vez con respecto a $E$ I Monastil. Por medio, un extenso llano cuaternario, el conocido triángulo AspeMonforte-Novelda, de muy alta productividad agraria y buenas comunicaciones, donde por otro lado los itinerarios clásicos ubican la mansio Aspis. Aqui se insertaría el asentamiento de Las Tres Hermanas, como un elemento más de la trama demográfica, en el límite del teórico territorio y junto a la vía de comunicación que conduce al mar. Alejado de los suelos de la vega del río, su función, más allá del testimonio del poder local dada su posición elevada y previsible majestuosidad, debe ir ligada al flujo de personas y objetos que deambulaban por esta ruta: productos agropecuarios por las mercancías suntuosas que llegan por el Mediterráneo. Una posta, una parada al atravesar un nuevo territorio que incluiría todo tipo de relaciones comerciales en las que participa directamente.

Ubicado en el espacio, las coordenadas temporales certifican su papel en el tráfico mercantil. A caballo entre los siglos $V$ y IV a.n.e. asistimos al apogeo máximo de la importación de productos áticos (ROUILLARD, 1991; SALA, 1994), y desde los centros receptores costeros se inicia una redistribución hacia las tierras del interior que favorecerá por un lado las relaciones comarcales, potenciando a la vez la integración cultural de las distintas comunidades ibéricas, y por otro el enriquecimiento progresivo de las élites dirigentes. Los beneficios serían no sólo económicos, liberando una parte de la producción agropecuaria local hacia el comercio, sino también por los factores políticos implícitos en estas relaciones mercantiles, ya que éstas

\footnotetext{
${ }^{6}$ La prospección que uno de los autores (JRGG) realiza en la actualidad de estos terrenos, como proyecto de Memoria de Licenciatura, ha proporcionado la localización de un nuevo asentamiento ibérico: El Tolomó.
} 
suponen el reconocimiento expreso de una autoridad que actúa de interlocutora y al mismo tiempo, ésta encuentra una serie de objetos suntuarios con cuya ostentación se facilita su preeminencia social y política dentro de la comunidad.

Es sintomático al respecto el establecimiento en estas fechas de auténticos emporia situados junto a la costa que actúan de centros receptores de primer orden. El caso más evidente quizás sea L'Illeta de El Campello, pero hemos de admitir una función similar para La Picola en el sinus llicitanus. Del primero, esta función ha sido explícitamente aceptada a partir de las investigaciones de E. Llobregat (LLOBREGAT, 1993), y trabajos más recientes (GARCÍA y GRAU, 1998) han continuado esta línea ofreciendo interesantes datos acerca del recorrido de estas mercancías hacia el interior. Por lo que se refiere a La Picola, el equipo hispano-francés que ha llevado a cabo su excavación identifica el yacimiento como el puerto de La Alcudia (MORET y BADIE, 1998), y ya fuera desde La Picola o desde La Alcudia podemos razonablemente imaginar una circulación de estos bienes hacia las tierras del interior. De nuevo en este caso, tenemos presente que la redistribución de dichas mercancías pudo estar sujeta a intereses políticos que condujeran a un tráfico selectivo pero no tenemos actualemnte datos que avalen esta hipótesis. En cualquier caso, el tráfico comercial generado en estos siglos posibilitó en general el enriquecimiento cuantitativo y cualitativo de la sociedad ibérica y en particular de unas élites dirigentes que no dudaban en hacer pública ostentación de su poder.

\section{BIBLIOGRAFÍA}

ABAD CASAL, L. y BENDALA GALÁN, M.,1989: El Arte Ibérico, Cuadernos de Historia del Arte, 10, Historia 16, Madrid, 161 págs.

ABAD CASAL, L. y SALA SELLÉS, F.,1993: El poblado ibérico de El Oral (San Fulgencio, Alicante). Trabajos Varios del S.I.P., n 90 , Valencia, 296 págs.

1995: "Una propuesta de descripción, sistematización e interpretación de materiales arqueológicos". Extremadura Arqueológica, V. (Homenaje a la Dra Milagros Gil-Mascarel), Junta de Extremadura, Badajoz, 265-277

ABAD CASAL, L., SALA SELLÉS, F. y ALBEROLA BELDA, E.M., 1995-97: "La necrópolis y el área sacra ibéricos de Las Agualejas (Monforte del Cid, Alicante)“, Lucentum, XIV-XVI, 7-18, Universidad de Alicante.

ALMAGRO-GoRBEA, M., 1988: "Pozo Moro. Un monumento funerario ibérico orientalizante", Madrider Mitteilungen, 24 177-293, Mainz.

ALMAGRO-GORBEA, M. y RAMOS FERNÁNDEZ, R., 1986: "El monumento ibérico de Monforte del Cid", Lucentum, $\mathrm{V}, 45-63$, Universidad de Alicante.
ALMAGRO-GORBEA, M. y DOMÍNGUEZ DE LA CONCHA, A., 1988-89: "El palacio de Cancho Roano y sus paralelos arquitectónicos y funcionales", Zephyrus, XLIXLII, 339-382, Salamanca.

ARASA I GIL, F. y ROSSELLÓ I VERGER, V.M., 1995: Les vies romanes al territori valencià, C.O.P.U.T.Generalitat Valenciana, Valencia, 141 págs.

BADAL GARCÍA, E., 1990: "Análisis anatómico de un fragmento de madera del yacimiento arqueológico de Tabayá (Aspe, Alicante)", Homenaje a Jerónimo Molina, Academia Alfonso X El Sabio-CajaMurcia, Murcia, 95-97.

GARCÍA GANDÍA, J.R. y MORATALLA JÁVEGA, J., 1999: "Un primer avance sobre un ejemplo de arquitectura de prestigio ibérica: Las Tres Hermanas (Aspe, Alicante)", Revista del Vinalopó, 2, 151-172, Centre d'Estudis Locals de Petrer.

GARCÍA MARTíN, J. M. y GRAU MIRA, I., 1998: "Les ceràmiques gregues als jaciments ibèrics de l'Alcoià $i$ el Comtat", Recerques del Museu d'Alcoi, 6, 119-130 , Alcoi.

GRAU MIRA, I. y MORATALLA JÁVEGA, J.,1998: EI poblamiento de época ibérica en el Alto Vinalopó, Fundación Municipal "José María Soler", Villena, 143 págs.

HERNÁNDEZ ALCARÁZ, L. y SALA SELLÉS, F., 1996: El Puntal de Salinas. Un hábitat ibérico del S. IV aC en el Alto Vinalopó, Fundación Municipal "José María Soler", Villena, 183 págs.

LLOBREGAT CONESA, E. A., 1988: "Un conjunto de templos ibéricos del siglo IV a. de $C$. hallado en las excavaciones de la Isla de Campello", Homenaje a Samuel de los Santos, 137-143, Albacete. 1993: "L'Illeta dels Banyets (El Campello, Camp d'Alacant). ¿Fou un emporion?", Homenatge a Miquel Tarradell, 421-428, Curial Edicions Catalanes, Barcelona.

MALUQUER DE MOTES, J., HUNTINGFORD, E., MARTÍN, R., RAURET, A.M., PALLARÉS, R. y VILA, M.V., 1986: Arquitectura i urbanisme ibèrics a Catalunya, Universidad de Barcelona, 104 págs,

MONEO, T., 1995: "Santuarios urbanos en el Mundo Ibérico", Complutum, 6, 245-255, Universidad Complutense, Madrid.

MORATALLA JÁVEGA, J. 1994: "La agricultura de L'AlcoiàComtat en Epoca Ibérica: datos para su estudio", Recerques del Museu d'Alcoi, 3, 121-133, Alcoi.

1999: "La tecnología del hierro como fundamento del crecimiento económico de Epoca Ibérica Clásica: El ejemplo del sur de Alicante", // Congreso de Arqueología Peninsular (Zamora, 1996), t. III, 375-387, Zamora.

MORET, P. y BADIE, A., 1998: "Metrología y arquitectura modular en el puerto de La Picola (Santa Pola, Alicante) al final del siglo V a.C.", Archivo Español de Arqueologia, 71, 53-61, Madrid.

MOROTE BARBERÁ, G., 1979: "El trazado de la Vía Augusta desde Tarracone a Carthagine Spartaria. Una aproximación a su estudio", Saguntum, 14, 139-159, Valencia.

OLCINA DOMENECH, M. (ed.), 1997: La llleta dels Banyets (El Campello, Alicante). Estudios de la Edad del Bronce y Época lbérica, Museo Arqueológico Provincial de Alicante, 251 págs.

PAVÍA, A. y PRIETO, A., 1998: "Relieve e hidrografía", en Aspe, Medio Físico y Aspectos Humanos, Ayuntamiento de Aspe.

POVEDA NAVARRO, A., 1996: "El Monastil: del Oppidum ibérico a la Civitas Hispanorromana de Elo", XXIII Congreso Nacional de Arqueología (Elche, 1995), tomo I, 415-426, Elche. 
PRADOS TORREIRA, L., 1994: "Los santuarios ibéricos. Apuntes para el desarrollo de una arqueología del culto", Trabajos de Prehistoria, 51, 127-140, Madrid.

RAMÓN, J., 1991: Las ánforas púnicas de Ibiza, Conselleria de Cultura, Educació i Esports, Govern Balear.

RIBERA LACOMBA, A., 1982: Las ánforas prerromanas valencianas, Trabajos Varios del SIP, 73,Valencia, 141 págs.

RODERO RIAZA, A., 1991: "Las ánforas del Mediterráneo occidental en Andalucía", Trabajos de Prehistoria, 48, 275-298, Madrid.
ROUILLARD, P., 1991: Les grecs et la Péninsule Ibèrique du VIII au IV siècle avant Jésus-Christ, Publications du Centre Pierre Paris, 21, París, 467 págs.

SALA SELLÉS, F., 1994: "La cerámica de importación en los siglos VI-IV a.C. en Alicante y su repercusión en el mundo indigena", Iberos y griegos: Lecturas desde la diversidad. Simposio Internacional celebrado en Ampurias, 3 al 5 de abril de 1991 (Huelva Arqueológica, XIII, 1, 275-296).

SPARKES, E. y TALCOOTT, L., 1970: The Athenian agora, $X I I$. Black and plain pottery of $6^{\text {th }}, 5^{\text {th }}$ and $4^{\text {th }}$ centuries B.C. Princeton. 